\title{
Does Property Ownership Lead to Participation in Local Politics? Evidence from Property Records and Meeting Minutes*
}

\author{
Jesse Yoder $^{\dagger}$ \\ Department of Political Science \\ Stanford University
}

January 24, 2020

\begin{abstract}
Homeowners and renters have participated in politics at different rates throughout American history, but does becoming a property owner motivate an individual to participate in local politics? I combine deed-level property records in California and Texas with an original dataset on individual comments in local city council meetings to study the role of property ownership in shaping costly forms of political behavior, and I document large inequalities in who participates at city council meetings. I also link property records to individual-level contribution records and administrative voter files and find that becoming a property owner increases an individual's political activity. Over and above voting in local elections, property ownership motivates individuals to participate in local city council meetings and donate to candidates. These findings illustrate how the experience of homeownership leads property owners to become much more active in local politics.
\end{abstract}

${ }^{*}$ For comments and suggestions, the author thanks Katie Einstein, Justin Grimmer, Andy Hall, Zhao Li, Zac Peskowitz, Dan Thompson, Matt Tyler, and participants in Stanford's Democracy Policy Lab meetings, the 2019 Midwest Political Science Association conference, and the 2019 American Political Science Association conference.

${ }^{\dagger}$ Jesse Yoder is a Ph.D. Candidate in the Department of Political Science at Stanford University (yoderj@stanford.edu; 616 Serra Mall, Stanford, CA 94305). 
"It is in our national interest that more people own their own home. After all, if you own your own home, you have a vital stake in the future of our country."

-President George W. Bush, December 16, $2003^{1}$

\section{Introduction}

Cleavages between property owners and non-owners have defined many political systems, dating back centuries. ${ }^{2}$ In the United States, property ownership has long been a central component of American political thought. ${ }^{3}$ In fact, until the middle of the nineteenth century, owning property was a formal prerequisite for being able to cast a ballot in many states. ${ }^{4}$ The US government has also heavily subsidized homeownership throughout its history, raising questions about the role of such policies in either mitigating or perpetuating inequality, both economic and political. ${ }^{5}$ On one hand, with the expansion of the franchise to nonproperty owners and decreasing barriers to participation, modern-day renters might have similar opportunities as homeowners to have their preferences expressed in public policy. On the other hand, the empirical reality is that property owners and non-owners participate in politics at very different rates, raising the question about how property owners might be advantaged in electoral politics. ${ }^{6}$

Despite these long-standing differences, there remains little empirical evidence about how becoming a property owner changes an individual's political behavior in the US. While the participation of homeowners could be the result of pre-existing socioeconomic differences between homeowners and renters (Verba, Schlozman, and Brady 1995), the economic incentives associated with property ownership could also be driving part of these differences. An

\footnotetext{
${ }^{1}$ https://georgewbush-whitehouse.archives.gov/news/releases/2003/12/20031216-9.html

${ }^{2}$ See, for example, Plato's The Laws, Aristotle's Politics, and John Stuart Mill's Considerations of Representative Government.

${ }^{3}$ For example, see James Madison's Federalist No. 10.

${ }^{4}$ For a review of suffrage expansion in the United States, see Engerman and Sokoloff (2005).

${ }^{5}$ https://www.nytimes.com/2017/05/09/magazine/how-homeownership-became-the-engine-of-americaninequality.html

${ }^{6}$ Inequality in political participation on the basis of property ownership relates to one of the longest running literatures in political economy, which explores distributional conflict between individuals with wealth and those without it (e.g., Meltzer and Richard 1981; Acemoglu and Robinson 2005).
} 
emerging literature on housing and political behavior uses survey experiments to understand attitudes of homeowners and renters toward local housing development (e.g., Hankinson 2018; Marble and Nall 2018; Wong 2018). Einstein, Palmer, and Glick (2018b) finds that participants in local planning and zoning board meetings are more likely to be older, male, and regular voters, on average, and they overwhelmingly oppose local housing development. ${ }^{7}$ Hall and Yoder (2018) links property records to voter files in Ohio and North Carolina, finding that homeownership leads individuals to participate more in local elections, particularly when zoning issues are on the local ballot.

Adding to this burgeoning literature, I answer the following question: How does becoming a property owner shape individuals' participation in local politics? Descriptively, homeowners and renters in the United States differ on several attributes. Figure 1 illustrates a few notable differences between homeowners and renters over the last fifty or more years, using data from American National Election Studies (ANES) respondents. In the top left figure, I show that homeowners - plotted in light gray - are older on average than renters, plotted in black. This age difference has even widened slightly over the last several decades. In the top right figure, I show that homeowners are more likely than renters to report an income in the top tercile of the income distribution. Aside from compositional differences, homeowners and renters participate in politics at different rates. ${ }^{8}$

To move beyond descriptive differences and test the causal link between property ownership and political behavior, I combine individual-level administrative data on property records, voting, political contributions, and an original dataset on public statements made by individuals at local city council meetings. The analyses span from 2000 at the earliest to 2018 at the latest and include over 3.5 million unique individuals from California and

\footnotetext{
${ }^{7}$ This raises concerns that the structure of local meetings presents barriers to entry for disadvantaged groups (Fung 2006). Moreover, restrictions on development also correlate with racial segregation in American cities (Trounstine 2018).

${ }^{8}$ The middle two plots in Figure 1 show that homeowners, again in light gray, are more likely to report having voted in the most recent presidential election and to report having made a political contribution. The final two plots show that homeowners and renters seem to have different political preferences, on average. Homeowners self-identify as Republicans at higher rates than renters, while they self-identify as Democrats at lower rates than renters.
} 
Figure 1 - Descriptive Differences between Homeowners and Renters in the United States, ANES Cumulative File. Each plot shows a line graph, shown separately for homeowners in light gray and renters in black in each plot. Year is on the $\mathrm{x}$-axis.
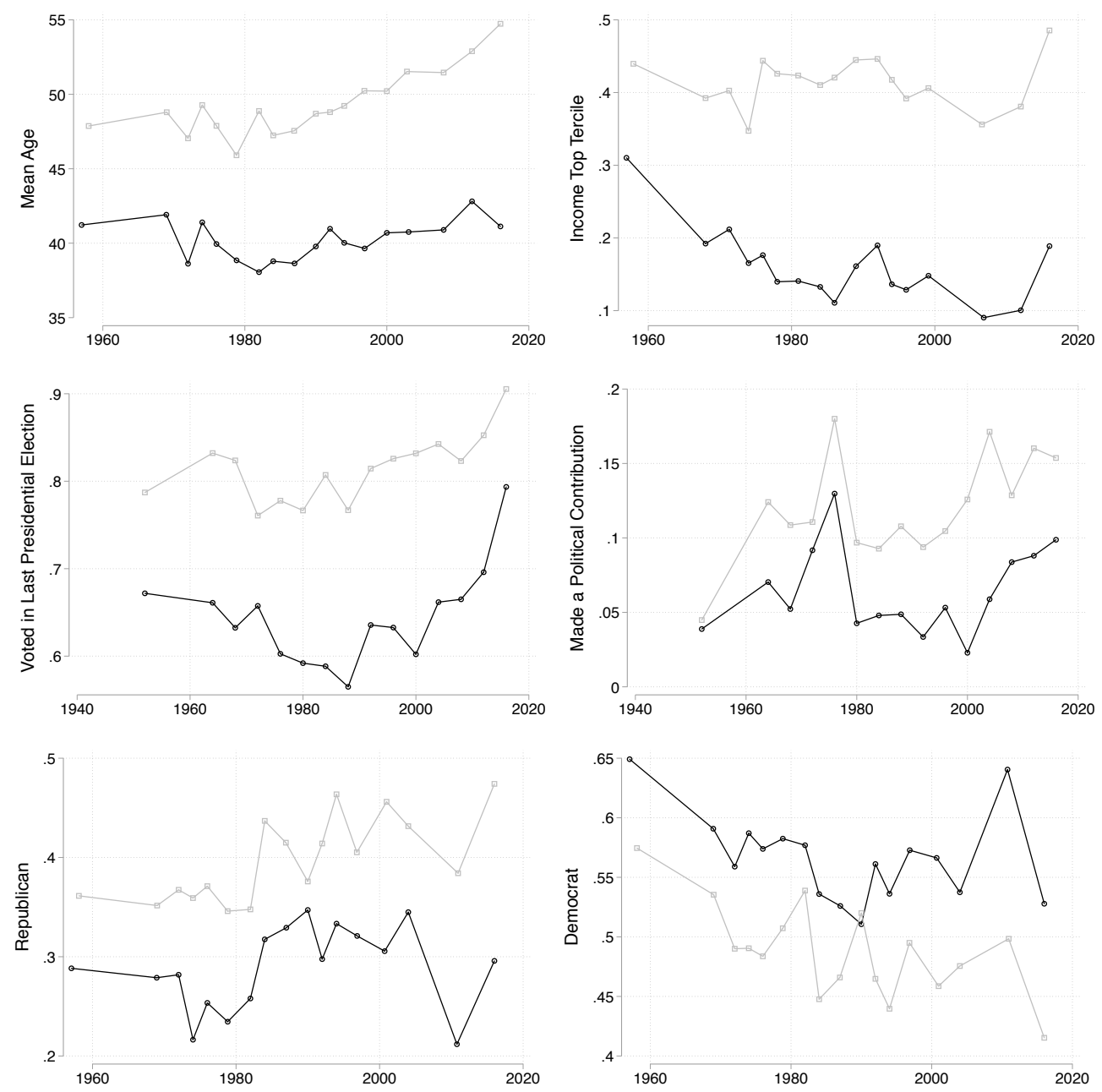

Texas, which offers enormous variation across place and time. Using a series of difference-indifferences designs, I find that becoming a property owner increases many forms of political activity: individuals become more likely to participate in local city council meetings, vote in local elections, and donate to candidates in state and federal elections. One of the main advantages of this study is that I observe the same individual's political behavior both before and after they become a homeowner, meaning I can control for fixed, unobservable characteristics of an individual that affect their likelihood of political participation. A series of follow-up analyses suggests that these changes cannot be wholly attributed to changes in 
wealth or age, two important potential time-varying confounders. I also document massive inequalities in the types of individuals who participate in local political meetings compared to those who do not. Consistent with previous research, I find that participants in local meetings are more likely to be men, regular voters, and older, on average (Einstein, Palmer, and Glick 2018b). These differences vary widely across settings, and I show suggestive evidence that these differences are likely a function of homeowners and renters prioritizing different local issues, coupled with differing topic salience across cities. ${ }^{9}$

Studying individual-level comments and donations also provides other advantages over simply examining turnout. Individuals in large electorates are unlikely to cast a pivotal vote regardless of their homeownership status, so increases in turnout as a result of homeownership would likely come from lowering costs of participation (Downs 1957; Riker and Ordeshook 1968). ${ }^{10}$ Given that comments in local meetings are an important way constituents provide information to local politicians (Einstein, Glick, and LeBlanc 2017), it is likely a more effective and consequential form of political participation than voting (Brady, Verba, and Schlozman 1995) or making a political contribution (Ansolabehere, De Figueiredo, and Snyder 2003). The text of public comments in local meetings also sheds light on what motivates individuals to participate in local politics. Using these statements, I find that homeowners and renters focus on different local issues, even after controlling for differences in topic frequency across cities and over time. Homeowners prioritize issues related to development, traffic, and historic preservation, while renters prioritize topics like politicing and community programming. ${ }^{11}$

\footnotetext{
${ }^{9}$ Rising housing wealth tends to be concentrated in major coastal markets, and "it is concentrated among the richest members of older cohorts - that is, on those who already owned homes several decades ago, before binding constraints on new housing construction were imposed." (Glaeser and Gyourko 2018).

${ }^{10}$ Becoming a homeowner might decrease an individual's cost of voting in several ways. Most notably, homeownership might decrease the costs of voting by not having to update one's voter registration frequently, which voters must do after moving and is a costly activity (e.g., Squire, Wolfinger, and Glass 1987; Highton 2004; Kim 2019). Second, becoming a homeowner might make individuals more accessible or easier to contact for voter mobilization, either through door-to-door mobilization (Green, Gerber, and Nickerson 2003) or direct mailers (Gerber, Green, and Larimer 2008).

${ }^{11}$ This also relates to a recent literature, developed mostly in economics, that maps an individual's portfolio of assets to their political views (e.g., Jha and Shayo 2019).
} 
Overall, the evidence suggests that becoming a property owner changes how an individual participates in local politics - and that it boosts their involvement in making costly efforts to shape local politics in the real world. Normatively, these findings illustrate an important trade-off. On one hand, it might be desirable that the structure of local politics in the US encourages homeowners - who have an important share of their wealth concentrated in an immobile asset, and therefore have a large financial stake in the local community to participate. On the other hand, given the baseline level of wealth necessary to become a property owner, the increase in participation among those who become property owners seems to come at the cost of an electorate that is representative of the broader population, and that property ownershi, at least in part, seems to lead to participatory inequalities in local politics.

\section{Data on Homeownership and Political Behavior}

To study the effect of homeownership on political behavior, I use individual-level administrative data from four sources. The first dataset has information on property ownership, collected from public records in each county in the United States and provided by CoreLogic, a private data vendor. The dataset includes information about individual properties, including property type, full name of the property's owner(s), full address, sale date, sale price, assessed value, and other information in each year from 2000-2017. I combine this information with political behavior from three other sources: (1) an original dataset on individuals' public statements in local city council meetings in Dallas, Texas; Houston, Texas; and Palo Alto, California; assembled from publicly available meeting transcripts, (2) administrative voter files from the entire states of California and Texas, provided by voter file vendor L2, and (3) political contributions in state and federal elections from the Database on Ideology, Money in Politics, and Elections (DIME) (Bonica 2014, 2016). 
Table 1 - Information Included in Various Data Sources. Each column denotes a data source, and checkmarks indicate features or observable information in that data source.

\begin{tabular}{lcccc}
\hline \hline & Property Records & Voter File & Contributions & Local Meetings \\
\hline Individual-level & $\checkmark$ & $\checkmark$ & $\checkmark$ & $\checkmark$ \\
Full Name & $\checkmark$ & $\checkmark$ & $\checkmark$ & $\checkmark$ \\
Full Address & $\checkmark$ & $\checkmark$ & $\checkmark$ & $\checkmark$ \\
Statewide Coverage & $\checkmark$ & $\checkmark$ & $\checkmark$ & \\
Homeownership Status & $\checkmark$ & $\checkmark$ & & $\checkmark$ \\
Local Political Participation & & $\checkmark$ & $\checkmark$ & $\checkmark$ \\
National Political Participation & & $\checkmark$ & $\checkmark$ & \\
Political Preferences & & $\checkmark$ & & \\
Date of Birth & & $\checkmark$ & \\
Gender & & & \\
Party Affiliation & &
\end{tabular}

Each of these datasets provides unique advantages, which I summarize in Table 1 . The voter file has individual turnout in local elections over a long period of time, from 2000-2017. That said, the disadvantage is that turnout, even in local elections, is one of the least costly observable forms of political participation. Vote choice is also anonymous, so it is difficult to infer how individuals' political preferences might be changing by only observing the turnout decision.

Local Meetings Data and Case Selection For a more costly form of participation, I link individuals to political contribution records in state and federal elections from 2000-2014, and I also assemble an original dataset on public statements individuals make at local city council meetings. I collect city council meeting transcripts from Dallas, Texas (2000-2018), Houston, Texas (2004-2014), and Palo Alto, California (2002-2010). I chose these cities because of data availability. To be able to merge individual comments to the voter file and property records requires name and address, and most city council meeting transcripts often only include the full name of each individual who comments. Nonetheless, these cases provide some interesting variation in the salience of housing as a local issue. Palo Alto, California has become a focal point for the rise of "not in my backyard" politics, or NIMBYism, where homeowners seek to restrict local housing development to protect their home values, even in 
cases where these restrictions conflict with partisan ideology (e.g., Marble and Nall 2018). Becoming a homeowner might increase participation at local meetings in settings like Palo Alto, where housing development is a central feature of local political debate, compared to settings like Dallas and Houston. The cities also offer considerable variation in size, population characteristics, and government chracteristics. $^{12}$

For each city, I observe the full name and address of each individual who makes a public statement at a city council meeting along with the topic and, in many cases, the full text of their actual spoken statement. In other cases, meeting transcripts provide a summary of the public speaker's comments. Using these transcripts, I code every instance of a public comment, preserving the name and address of each commenter in order to link them to the voter file, property records, and donation records. The final dataset includes over 7,000 public statements made in local meetings across the three cities.

\subsection{Linking Individuals Across Data Sources}

I link individuals using full name and address, which are available in each of the four main data sources: (1) the administrative voter file, (2) property records, (3) individual contribution records, and (4) city council meeting participation. In this section, I describe the procedure for linking individuals across these four sources.

\subsubsection{Administrative Voter File}

I begin with the full voter file for the states of California and Texas. ${ }^{13}$ For each individual, the file contains full name and address, registration date, date of birth, gender, party affiliation, and turnout history in local and national elections from 2000-2017.

\footnotetext{
${ }^{12}$ Dallas and Houston are large cities with larger African-American population populations (24.3\% and $22.9 \%$, respectively) than Palo Alto (1.2\%). Palo Alto has a higher homeownership rate $(55 \%)$ than Dallas (42\%) and Houston (43\%). Palo Alto residents also have higher educational attainment - $81 \%$ have a Bachelor's Degree or Higher - than in Dallas (32\%) and Houston (32\%). While Houston operates with a mayor-council form of government, Palo Alto and Dallas have a council-manager form of government.

${ }^{13}$ I use the voter file current as of September 2018 for each state.
} 


\subsubsection{Linking Individuals to Property Records}

I link the voter file with property tax and deed records for the entire states of California and Texas. The property records include the full name of each property's owner(s), address, property type, sale date, sale price, assessed value, and other information. To pre-process the property records, I subset to owners of the following property types: single family residence, condominium, duplex, and apartment. If properties have two owners, I treat each owner as a unique record for the purposes of the merge. ${ }^{14}$ Following recent work in political science on merging individuals across large scale administrative datasets, I implement fastLink (Enamorado, Fifield, and Imai 2019), a probabilistic record linkage procedure, in order to merge records on first name, last name, zip code, and full street address. ${ }^{15}$ Because each of the datasets contains millions of records, I first block on zip code, and then proceed by matching probabilistically on last name, first name, and full street address. ${ }^{16}$ I set a threshold of 0.85 to declare two records a match, meaning the posterior probability that the two records are a match exceeds 85\%. Following Enamorado, Fifield, and Imai (2019), I use the match probabilities in the analysis in order to incorporate the merge uncertainty into the post-merge analysis. ${ }^{17}$ After selecting the best match using this procedure, I preserve both

\footnotetext{
${ }^{14}$ It remains possible, and perhaps common, that a married or cohabiting couple lives at a property but only one person is listed as the owner of the property. In that case, individuals who are not listed as an owner would be coded as a non-homeowner for the purposes of my analysis. This raises the question of what the gender distribution of property owners is in my data. Using information on gender from the voter file, I gender differences by property ownership: $49 \%$ of homeowning registrants are listed as female, while $54 \%$ of non-homeowning registrants are listed as female.

${ }^{15}$ Recent work in political science finds that using this linking procedure often outperforms deterministic procedures when merging across large scale administrative datasets (Enamorado, Fifield, and Imai 2019). Specifically, I use the fastLink package in R to implement the merge. Using probabilistic linking presents a trade-off: while deterministic procedures limit the potential for false positives, they sacrifice in terms of the merge rate and false negative rate because they require exact matches on all variables used in the merge. Probabilistic procedures increase the number of potential matches and bring down the false negative rate - at the risk of increasing the number of false positives. Because the false positive rate is often low when linking large administrative datasets with a lot of information (full name and address), I opt to use the probabilistic procedure in order to increase the match rate.

${ }^{16}$ Specifically, for the approximate string matching I use the Jaro-Winkler distance, and I set the JaroWinkler penalty parameter $p$ equal to 0.1 .

${ }^{17} \mathrm{I}$ describe how I incorporate this merge uncertainty into the estimation in more detail in Section 4.
} 
unmatched voter file records and unmatched property records for subsequent merges. ${ }^{18}$ This means that individuals in the voter file who do not match to the property records using this procedure are coded as non-homeowners, and homeowners who do not match to the voter file are included and coded as non-voters. I describe the procedure in more detail in Section A.1. Overall, many individuals in the voter file are identified as homeowners: $55.91 \%$ of individuals in the voter file are homeowners based on this linkage procedure. ${ }^{19}$

\subsubsection{Linking Individuals to Political Contribution Records}

Next, I merge in political contribution records for the entire states of California and Texas for each year from 2000 through 2014. These records contain itemized political contributions to candidates or committees for federal and state offices. ${ }^{20}$ Federal races include Presidential, US House, and US Senate races, while state races include elections for Governor and state legislature. Because the contributions data contains much of the same information as the voter file and property records, namely zip code, last name, first name, and self-reported address, I use the same probabilistic linkage procedure as the one described for linking the voter file to property records. One limitation of this dataset is that the address is selfreported, meaning a contributor could report a PO Box or a work address, making them more difficult to link to their voter file records or property records. For this reason, the false negative rate is a bit higher $(29 \%)$ compared to merges using the other datasets. I output the full population of registered voters and property owners, but it now includes information on whether the individual made a contribution in each year from 2000 through 2014, coded as a 0 if $\mathrm{I}$ fail to find a contribution record for that individual. For those who made a donation, I observe the amount of all donations, along with the office, party, and ideology

\footnotetext{
${ }^{18}$ In some analyses I subset to individuals based on information only available in the voter file, in which case property owners that fail to merge to the voter file are dropped.

${ }^{19}$ The merge rates in California and Texas are $50.44 \%$ and $60.49 \%$, respectively, which are roughly consistent with each state's homeownership rate from the US Census (https://www.latticepublishing.com/blog/ states-with-the-highest-homeownership-rates).

${ }^{20}$ I choose to focus on California and Texas not only because they are large states, but because they also have the most complete records on contributions to candidates and committees for state offices.
} 
of the receiving candidates. ${ }^{21}$ Political donations in a given year are quite rare: about $0.4 \%$ of person-years in the dataset make an itemized contribution, overall. ${ }^{22}$

\subsubsection{Linking Individuals to City Council Meeting Participation}

Finally, I link individuals to an original dataset on public participation in local city council meetings. Each observation in the meetings data is a comment, accompanied by the individual's full name, address, zip code, and date of the local meeting. ${ }^{23}$ I pre-process the meetings data by collapsing the dataset so that the unit is a individual, and I generate a count of the total number of comments an individual makes in each year. I again rely on the linkage procedure described above. Pooling all three cities together, about $0.27 \%$ of residents make a comment at a local city council meeting at some point during the study period. This rate is higher in Palo Alto (1.78\%) compared to Dallas (0.29\%) and Houston $(0.21 \%)$.

\subsubsection{Summary}

The final dataset includes over 3.5 million unique individuals in California and Texas, whose vote history is observed since $2000 .{ }^{24}$ This dataset has two main limitations: first, the voter file is only observed at one point in time, September 2018, so I do not observe individuals who were registered but purged from the voter file before this date. If homeowners are purged from the voter at different rates than non-homeowners, this would induce bias in the estimated effect of homeownership. Hall and Yoder (2018) shows that the results for a similar analysis in North Carolina, where voter file histories are available, are very similar

${ }^{21}$ To measure ideology, I use the campaign finance (CF) scores assigned to candidates, which are constructed using campaign finance data (Bonica 2014).

${ }^{22}$ These rates are virtually identical in California and Texas.

${ }^{23}$ Zip code is available for the city council meeting transcripts in Houston, but only name and address are available in the Dallas and Palo Alto meeting transcripts.

${ }^{24}$ I code an individual-year as a 0 for voting, donating, and commenting if I do not observe them as having participated in a given year. If individuals move in from out of state, however, it is possible that they had participated previously in another state, so they should be coded as missing rather than as having not participated. If this is the case, I would be overestimating the effect of becoming a property owner on political behavior. To limit this potential bias, in many cases I also estimate effects only among those who have been registered in the state since the start of the panel so that I know that their behavior was observable over the course of the panel. 
when including and excluding purged voters - so this potential source of bias is unlikely to substantially affect the results. The second main limitation is the possibility of merge error. The false positive rate, where a match contains two different individuals individuals are linked, is often very low when using high-quality administrative datasets containing full name and address (Ansolabehere and Hersh 2017; Enamorado, Fifield, and Imai 2019). ${ }^{25}$ The main concern for this merge would be false negatives, where records in different datasets correspond to the same individual but they are not matched. Because these datasets are high quality, have low missingness, and are unlikely to have widespread misspellings in name and address, the false negative rate should be low compared to most probabilistic linking across administrative datasets. I report the estimated false positive and false negative rates in Section A.1 of the Appendix, and the estimates are reassuringly low, especially when linking the voter file to the property records, where the overall false positive rate is $0.52 \%$ and the overall false negative rate is $13.4 \%$.

\section{Characterizing Who Participates in Local Meetings}

With the resulting dataset, I characterize the types of individuals who participate in local city council meetings compared to other residents who do not. Figure 2 compares attributes of individuals who spoke at a Palo Alto city council meeting at some point from 2002-2010 with those who did not. Each graph plots the distribution of a given characteristic, and I do this separately for individuals who comment at local city council meetings (in blue) and for those who do not comment at local meetings (in gray). A few interesting patterns emerge. Participants in local city council meetings in Palo Alto are more likely to be registered to vote, older, male, political donors, and voters in local and national elections, on average. The differences in participation in local elections are massive: while non-commenters had a turnout rate of about $24 \%$ in local elections during this period, commenters had a turnout

\footnotetext{
${ }^{25}$ Moreover, Ansolabehere and Hersh (2017) show that nearly all registered voters in Texas are unique within last name, first name, zip code, and street number, so almost no false positives will be generated from duplicate records in the voter file for the variables I use for the merge.
} 
rate over $71 \%$. In Palo Alto, local meeting participants are also more likely to be Democrats and are slightly more liberal according to the CF score among donors. ${ }^{26}$ Lastly, commenters are much more likely to be homeowners (62\%) than non-commenters $(42 \%) .{ }^{27}$

It is possible - and perhaps even expected - that massive differences in the types of people who comment at local meetings and those who do not might not generalize to other settings Palo Alto for a few reasons. Both the types of individuals who live in Palo Alto and the most salient issues in the city are quite different from most other cities. Overall, Palo Alto has higher levels of political participation, both in local and national elections, compared to most areas of the United States. It also has many Democratic registrants: a majority of registrants affiliate with the Democratic party, while only about $11 \%$ of registrants affiliate with the Republican party. Palo Alto residents have very high education levels $-81 \%$ have a Bachelor's degree or higher. Its housing market is also quite out of the ordinary - the median home value exceeds $\$ 2$ million. And issues around housing and development much more salient local issues in Palo Alto than in the vast majority of US cities. All of these quirks raise the question of whether the observed differences between local meeting participants and non-participants generalize to other settings.

To test this, Figure 3 compares attributes of individuals who spoke at a Dallas city council meeting at some point from 2000-2018 with those who did not. Like Palo Alto, commenters in Dallas city council meetings are more likely than non-commenters to be registered to vote, older, male, political donors, and voters in local and national elections, on average. They are also slightly more liberal, looking both at the share that register as Democrats and the CF score score among donors. Commenters in Dallas are also more likely to be homeowners (49\%) than non-commenters (39\%), but this difference is much smaller than the homeownership gap in Palo Alto. This could be because the costs of participation are

\footnotetext{
${ }^{26} \mathrm{~A}$ smaller $\mathrm{CF}$ score indicates that donors donate to more liberal candidates.

${ }^{27}$ Conditional on owning a home, we see that participants in local meetings had an average home value of $\$ 764,750$, while non-participants had a larger average home value of $\$ 1,076,325$. This difference can be explained by the fact that local meeting participants are much older on average, and age is negatively correlated home value in California because Proposition 13 caps annual increases in assessment values for long-time residents.
} 
Figure 2 - Palo Alto City Council Commenters, 2002-2010. Commenters are shown in blue, while non-commenters are shown in gray. The unit of observation is a person-year. Registration year, birth year, female, and party registration are only available for individuals in the voter file. The logged contributions graph conditions on person-years in which a donation was made.
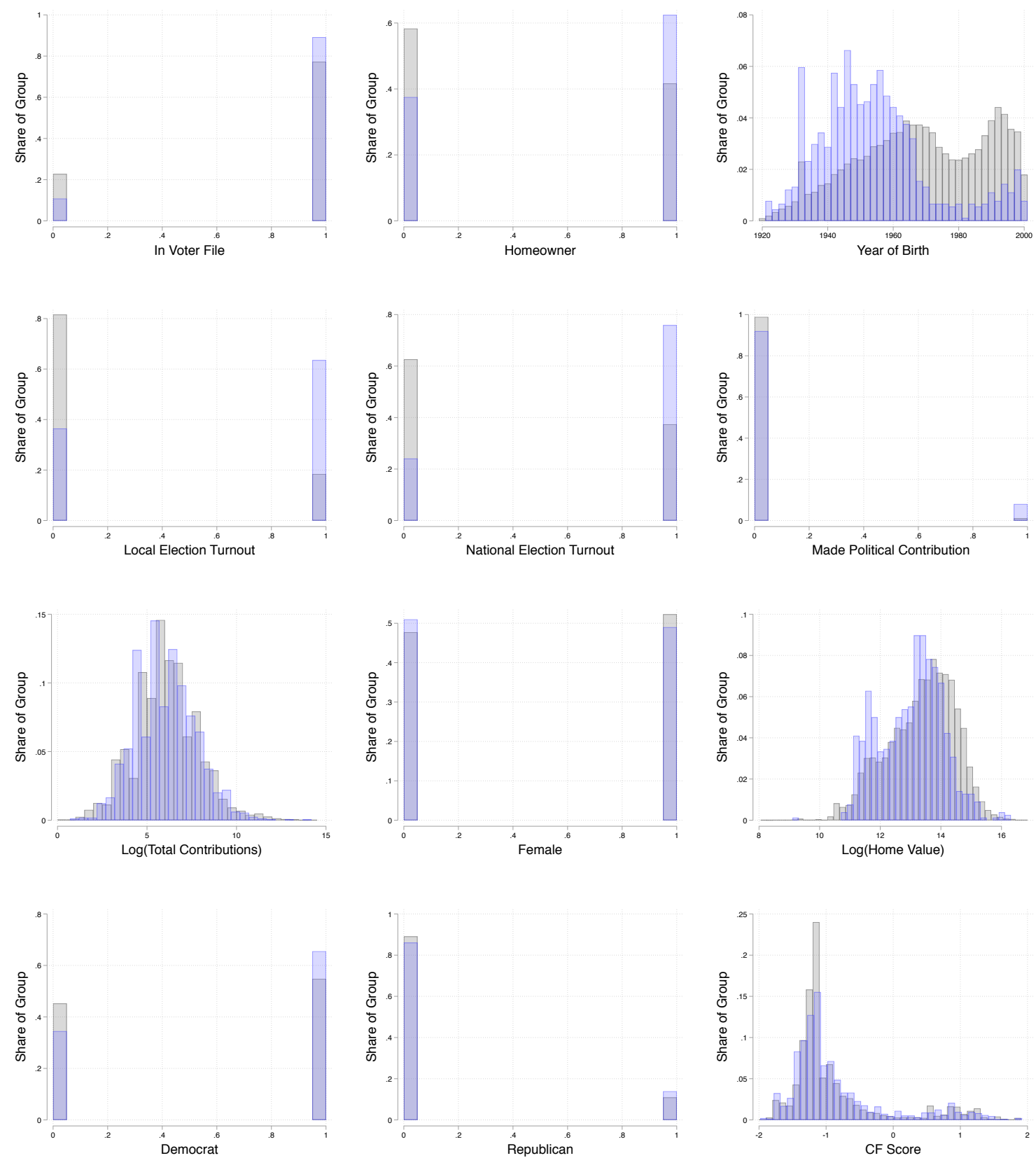

lower for renters if they live closer to City Hall, or because the salient topics at local meetings motivate homeowners more in Palo Alto than in Dallas. Figure A.2 in the Appendix shows 
Figure 3 - Dallas City Council Commenters, 2000-2018. Commenters are shown in blue, while non-commenters are shown in gray. The unit of observation is a person-year. Registration year, birth year, female, and party registration are only available for individuals in the voter file. The logged contributions graph conditions on person-years in which a donation was made.
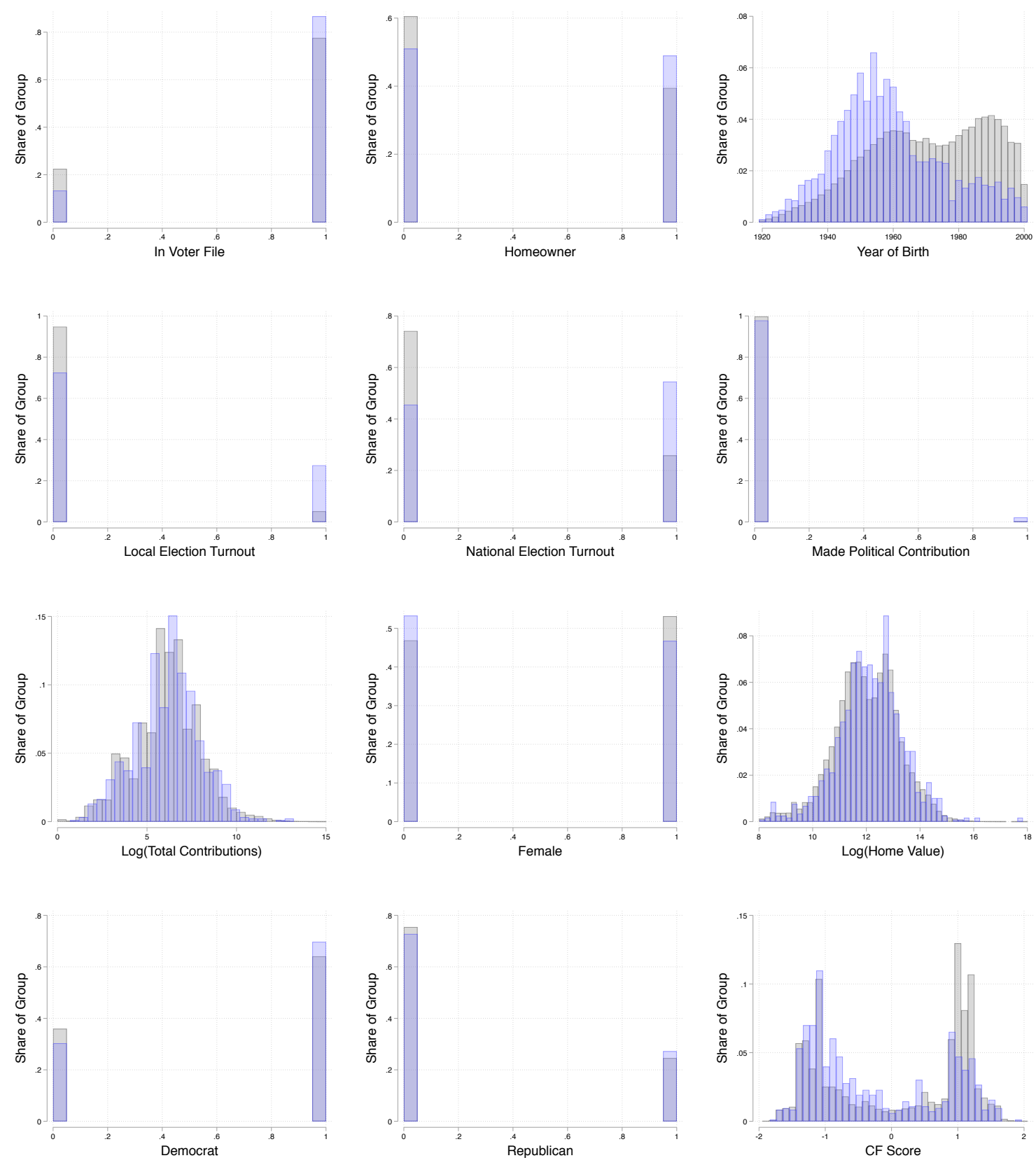

the same set of comparisons for local meeting participants in Houston, and the differences are all quite similar to those in Dallas. 
The first work to systematically document inequalities in participation in local planning and zoning board meetings finds participants in local meetings in Massachusetts are overwhelmingly homeowners (Einstein, Palmer, and Glick 2018a). Here, I build on this existing work and show that these inequalities in participation in local meetings extend to other settings, as well as for commenting in city council meetings in addition to meetings specifically about land use.

That said, the share of commenters that are homeowners varies substantially not only across city, but also over time within each city. As Figure 4 shows, the share of commenters in Palo Alto who are homeowners ranges from about 57\% (in 2008) to 75\% (in 2002). The share of commenters at local meetings in Dallas has increased from around $22 \%$ to over 57\% from 2000 to 2017. In Section 5 I show that homeowners and renters are motivated by different issues when commenting at local meetings, which could explain this variation within city over time. Later, I show that homeowners are more likely to make comments related to land use policies than are renters, holding city, time, and the meeting agenda fixed, which is consistent with the findings from Einstein, Palmer, and Glick (2018b) that homeowners are much more active in local politics when questions of land use are on the agenda.

Overall, this section provides systematic evidence documenting inequalities in participation in local city council meetings across different settings. Persistent inequalities in local participation emerge in each of the settings I study (participants are more likely to be older, male, voters, and political donors, on average). The gap in the homeownership rate of commenters and non-commenters, meanwhile varies widely across different settings: while in Palo Alto those who participate in local meetings are over 20 percentage points more likely to be homeowners than those who do not participate, in Dallas and Houston these gaps are substantially smaller. Our understanding of inequalities in political participation at the local level, therefore, requires attention to which types of issues are addressed in local meetings, and to what motivates homeowners and renters to participate. 
Figure 4 - Proportion of Commenters That Are Homeowners Over Time, by City. The figure plots the share of members of the public who comment at local city council meetings that are homeowners, over time and by city. The share of commenters that are homeowners varies from city to city, but also varies within city over time.

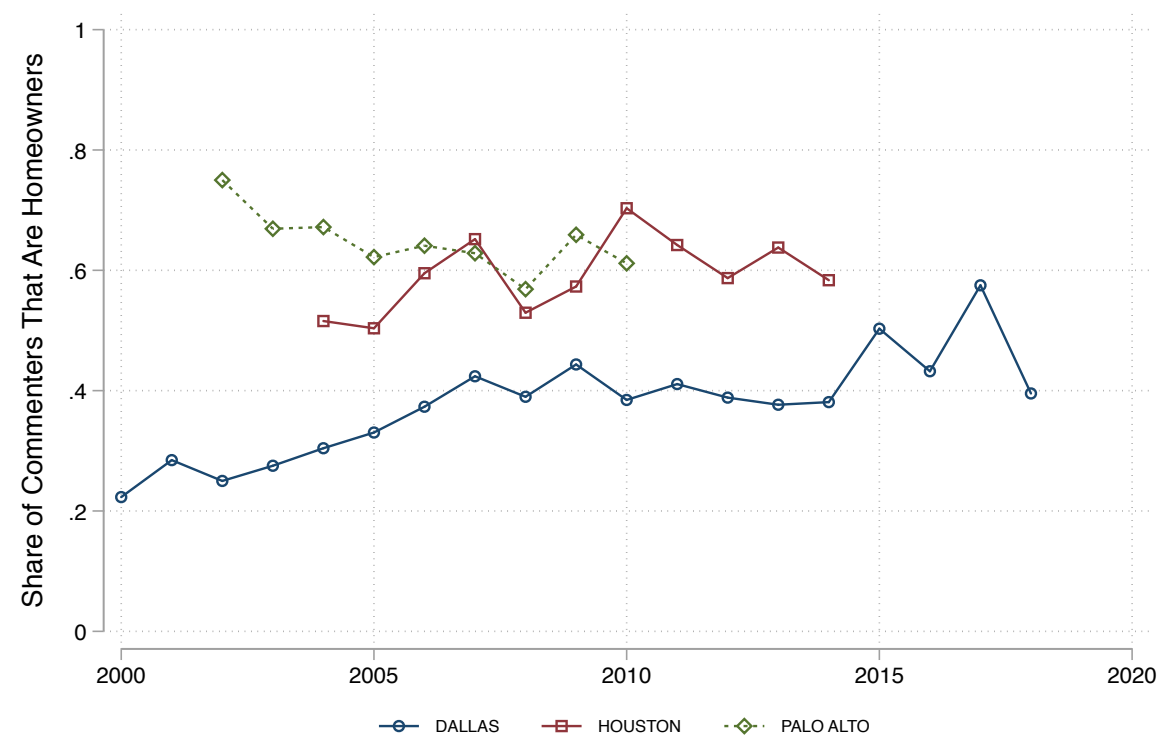

\section{Homeownership Increases Political Participation}

So far, I have shown that inequalities in local meeting participation across three different cities. Next, to gain some causal leverage on how homeownership changes an individual's political behavior, I employ a series of difference-in-differences designs to estimate how becoming a property owner affects various forms of political participation. Overall, I find that becoming a homeowner leads to increases in an individual's likelihood of commenting at local meetings, voting in local elections, and making political contributions.

For the purposes of these analyses, homeownership, as a conceptual treatment, represents a large monetary investment in an immobile asset situated in a particular geographic location. The counterfactual I have in mind, then, is what an individual homeowner's political behavior would have looked like had they chosen not to allocate a large fraction of their wealth in becoming a property owner. Another way to conceptualize this is as perhaps one of the most 
extreme examples of the effects reported in Jha and Shayo (2019), where an individual's wealth allocation might affect their downstream political behavior and preferences.

Of course, the main threat to this interpretation is that the decision to purchase a home is often correlated with other, often unobservable, changes in an individual's life - like marriage, changes in income, retirement, or other life events, which in turn might also affect political participation. While I clearly cannot randomize the decision for an individual to purchase a home, I use a series of strategies to test these different mechanisms, including making comparisons only among individuals who are the same age and who have similar levels of wealth, for example. I discuss this more below, but the results are suggestive of a direct effect of homeownership as an investment on an individual's participation in local politics.

\subsection{Evidence from Local City Council Meetings}

I first estimate the effect of becoming a property owner on an individual's participation in local city council meetings. Specifically, I estimate the following equation:

$$
\text { Commented }_{i t}=\beta \text { Homeowner }_{i t}+\gamma_{i}+\delta_{t}+\epsilon_{i t}
$$

where Commented Cot $_{i}$ is andicator for whether individual $i$ comments at a local city council meeting in year $t$, and Homeowner Hit $_{\text {is }}$ an indicator for whether individual $i$ is a property owner at any time in the year prior to the start of year $t$. In order to incorporate the uncertainty in the merge into the estimation, following Enamorado, Fifield, and Imai (2019) I multiply the homeowner indicator by the posterior probability of the records being a correct match. The intuition for this is straightforward: this procedure essentially downweights the magnitude of the treatment for individuals where it is less certain that they have been correctly matched. ${ }^{28}$ The individual $\left(\gamma_{i}\right)$ and year $\left(\delta_{t}\right)$ fixed effects control for time-invariant characteristics about individuals that affect their propensity to comment at local meetings, as well as common yearly shocks that affect the number of commenters at local city council

\footnotetext{
${ }^{28}$ The estimated effects are very similar when I do not account for the uncertainty in the merge procedure.
} 
meetings. Throughout the analyses, I vary the time fixed effects in several ways to estimate effects using different counterfactual trends.

Table 2 estimates the effect of becoming a property owner on participation at local city council meetings. Because participation in city council meetings is a low probability event, I subset to those who would go on to make a comment at some point over the entire study period, leaving about 6,000 unique individuals, totaling nearly 90,000 observations. ${ }^{29}$ In column 1, I pool all three cities together, and I that becoming a homeowner increases an individual's likelihood of commenting by about 3.9 percentage points, representing about a $50 \%$ increase over the outcome mean. ${ }^{30}$ The effect is precisely estimated: the $95 \%$ confidence interval ranges from about a 3.1 to 4.7 percentage point increase. I use zip code-by-year fixed effects to compute counterfactual trends using only individuals in the same zip code, but the results also hold across alternative sets of time fixed effects. One concern, however, with the estimates in column 1 is that I use all individuals, rather than ones who have lived in the area for the entire study period. For example, if someone were to become a property owner when they newly move into the city, I would count them as not having participated in the local city council meetings before moving there, even though they did not have the opportunity to participate, or they could have been participating in local meetings elsewhere. While I cannot observe the date an individual moved into the city, I can subset to individuals who were registered within the same state since before the start of the study period. This helps alleviate concerns about movers biasing the estimate upward in column 1 . In column 2, I estimate the effect just among those who were registered in the state during the entire study period. The estimate increases slightly to about 4.6 percentage points, and remains reasonably precisely estimated.

In columns 3, 4, and 5 I estimate the effect separately for each city in my data: Palo Alto, Dallas, and Houston, respectively. Becoming a property owner leads an individual to become

\footnotetext{
${ }^{29}$ The results are similar when I include individuals who never comment in the analysis.

${ }^{30}$ In Table A.11 in the Appendix, I estimate the same equation but use the logged total number of comments by an individual in a year as the outcome. The results are similar, suggesting that homeownership increases the total number of comments an individual makes in local meetings.
} 
Table 2 - Effect of Homeownership on Participation in City Council Meetings, 2000-2018.

\begin{tabular}{lccccc}
\hline \hline & & \multicolumn{4}{c}{ Commented $=1$} \\
& $(1)$ & $(2)$ & $(3)$ & $(4)$ & $(5)$ \\
\hline Homeowner & 0.050 & 0.055 & 0.165 & 0.072 & 0.043 \\
& $(0.005)$ & $(0.006)$ & $(0.053)$ & $(0.014)$ & $(0.007)$ \\
Observations & 83,580 & 53,496 & 6,831 & 16,275 & 30,390 \\
Number of Individuals & 5,978 & 3,870 & 759 & 1,085 & 2,026 \\
Outcome Mean & 0.077 & 0.083 & 0.161 & 0.055 & 0.081 \\
Sample & Pooled & Pooled & Palo Alto & Dallas & Houston \\
Always Registered & No & Yes & Yes & Yes & Yes \\
Individual FEs & Yes & Yes & Yes & Yes & Yes \\
Year-by-Zip Code FEs & Yes & Yes & Yes & Yes & Yes \\
\hline \hline
\end{tabular}

Robust standard errors clustered by individual in parentheses. The unit of observation is a person-year. Columns 2 through 5 restrict the sample to individuals registered to vote in the state before the panel. All columns restrict the sample to individuals who make a comment at some point over the length of the panel.

over 16 percentage points more likely - or nearly twice as likely - to comment at a local city council meeting in Palo Alto, where housing issues are most salient. Becoming a property owner leads individuals to comment more at local meetings in Dallas and Houston as well, but the effects are much more modest in size. While the variation in the variation in effect size across cities is insufficient to pin down one particular mechanism, it does suggest that individuals become especially motivated to participate after becoming a property owner in areas where housing issues are more salient, which is consistent with - but of course does not prove - the Fischel (2001) homevoter hypothesis, where homeowners become more attentive to local politics in places where incentives to protect property values are highest. Section 5 provides some support for this interpretation, as homeowners tend to focus on issues related to housing policy and development much more than renters, at least in the three cities that I study.

The validity of these difference-in-differences estimates relies on the parallel trends assumption, where changes in individuals' propensities to comment at local meetings after purchasing a home in a given year would have been the same as changes for those who did 
not purchase a home in that year. There are reasons to be skeptical of the parallel trends assumption in this particular case. Because homeownership is not randomly assigned, the obvious concern is that any time-varying confounder that correlates both with an individual's decision to purchase a home and with trends in local meeting participation would bias the estimates. One strategy to assess the difference-in-differences identification strategy is to add a variety of group-specific time trends to allow for different counterfactual trends. Later in the paper, I use this strategy to assess the influence of possible time-varying confounders, like wealth, age, planning for children, or other "adult roles" (Highton and Wolfinger 2001). Here, I assess the plausibility of parallel trends in a few other ways. First, in the first two columns of Table A.5 in the Appendix I include leads of homeownership, and I do not find strong evidence of pre-trending. Second, in Figures A.4, A.5, and A.6 I include several leads and lags of homeownership, modeling the dynamic effect of homeownership on the probability that an individual comments at local meetings in Palo Alto, Dallas, and Houston, respectively (Autor 2003; Angrist and Pischke 2008). The estimates show no evidence of an effect in the years before homeownership, with increasing effects in the first few years after becoming a homeowner. This pattern is a reassuring sign that the difference-in-differences identification assumption could hold in this case.

Lastly, I consider an alternative multi-period difference-in-differences estimator, which allows one to nonparametrically adjust for unit and time unobserved confounders at the same time. The estimator, proposed in Imai and Kim (2020), is equivalent to a weighted version of the standard two way fixed effects regression. I show the results sing this alternative estimator in Table A.6 in the Appendix, and the results remain similar.

\subsection{Evidence from Local Turnout}

So far, I have shown that property ownership increases an individual's likelihood of participating in local city council meetings, on average. Now, I turn to its effect on other forms of political participation, starting with turnout in local elections. I rely on difference-in- 
differences designs to estimate how property ownership changes turnout in local elections in California and Texas from 2001-2017. ${ }^{31}$ The outcome, Turnout $_{i t}$, is a simple indicator for whether individual $i$ voted in the general election in time $t$. I also use the same procedure from Section 4.1 for incorporating the merge uncertainty into this analysis.

Wealth is perhaps the most obvious potential time-varying confounder in this setup where individuals who become wealthier decide to purchase homes and also have different turnout trends for reasons other than the decision to purchase a home. As a first way to address this, I estimate the effect of property ownership on local election turnout only among those who become homeowners at some point - so every individual achieves the wealth status necessary to purchase a home at some point. These estimates, then, exploit variation in the timing of the decision to purchase a home, effectively requiring that changes in turnout among those who purchase a home in time $t$ would have been the same as changes in turnout among those who did not purchase a home in time $t$, but who would later go on to purchase one. This perhaps makes the parallel trends assumption more plausible than including individuals who never become homeowners, who likely have very different counterfactual local turnout trends from individuals who eventually own homes. ${ }^{32}$ In column 1 of Table 3 I include a separate set of year fixed effects for California and Texas, so that counterfactual trends for treated units are constructed only control units within the same state. In that specification, I find that property ownership leads to a 2.8 percentage point increase in local turnout. ${ }^{33}$ Because changes in local turnout are likely a function of unobserved features like the types of local races or candidates on the ballot, in column 2 I allow each zip code to have its own set of year fixed effects, which constructs counterfactual trends for treated units using only control individuals within the same zip code. The point estimate is similar, which helps

\footnotetext{
${ }^{31}$ Because there are tens of millions of individuals and nine local election cycles, there are computational constraints in the estimation. To simplify, I randomly sample $10 \%$ of zip codes in California and Texas to enter into the sample.

${ }^{32}$ In Table A.12 in the Appendix, I estimate the effect of property ownership on local turnout for the full sample, meaning I do not restrict the sample to eventual homeowners. The results are substantively similar.

${ }^{33}$ This estimate is similar in magnitude to the one found in Hall and Yoder (2018) for local election turnout in the state of Ohio.
} 
Table 3 - Effect of Homeownership on Political Participation in Local California and Texas Elections, 2001-2017.

\begin{tabular}{lcccc}
\hline \hline & & Turnout in Local Election $=1$ & \\
& $(1)$ & $(2)$ & $(3)$ & $(4)$ \\
\hline Homeowner & 0.028 & 0.027 & 0.023 & 0.022 \\
& $(0.000)$ & $(0.000)$ & $(0.000)$ & $(0.000)$ \\
Observations & $13,365,189$ & $13,365,189$ & $13,342,986$ & $6,980,535$ \\
Outcome Mean & 0.048 & 0.048 & 0.048 & 0.092 \\
Individual FEs & Yes & Yes & Yes & Yes \\
Year-by-State FEs & Yes & No & No & No \\
Year-by-Zip Code FEs & No & Yes & No & No \\
Year-by-Value-by-State FEs & No & No & Yes & No \\
Year-by-Age-by-State FEs & No & No & No & Yes \\
\hline \hline
\end{tabular}

Robust standard errors clustered by individual in parentheses. All columns include only individuals who become homeowners at some point during the study period. Year-by-Value fixed effects interact years with home value deciles.

alleviate concerns that people are becoming property owners in places where local turnout happens to be increasing anyway because of local factors like the types of races or candidates in these localities.

While I already subset on those who eventually become homeowners to make comparisons among individuals with at least enough wealth to eventually qualify to purchase property, in column 3 I use information on assessed home value to make even more fine-grained comparisons that make wealth less likely to be confounding the result. Following Hall and Yoder (2018), I include a separate year fixed effects for each home value decile in each state, which creates counterfactual trends for those who purchase a home using only individuals who did not purchase a home, but would go on to purchase a similarly priced home in the same state in the future. Again, the point estimate remains similar in magnitude. Lastly, another time-varying confounder could be changes in "adult roles," like marriage or planning for children. ${ }^{34}$ These factors might encourage long-term residency in a community, which positively correlates with political participation (Gay 2012; McCabe 2016). While I cannot

\footnotetext{
${ }^{34}$ Oliver and $\mathrm{Ha}$ (2007) show that participants in local elections tend to be highly informed community "stakeholders," like homeowners, parents of children, or long time residents.
} 
measure these directly, I use the individual birth dates to make more plausible counterfactual comparisons. In column $4 \mathrm{I}$ include a set of year fixed effects for every birth year in each state, so that I construct counterfactual trends for those who purchase a home using only control units who share the same birth year and are in the same state. ${ }^{35}$ The point estimate decreases slightly to 0.022 , but it still represents more than a $20 \%$ increase in local turnout over the baseline mean. This suggests that the effect is likely not explained solely by changes in wealth or taking on other adult roles.

To evaluate the plausibility of the parallel trends assumption, I include leads of property ownership in columns 3 and 4 of Table A.5 in the Appendix. These tests do not reveal evidence of pre-trending, which adds some credibility to the difference-in-differences identification assumption. I also include a lags and leads plot in Figure A.7 of the Appendix, finding that the effects are close to zero before property ownership and grow in local election cycles after becoming a property owner. I discuss these in more detail in Section A.7 of the Appendix, but this is a reassuring sign that parallel trends might hold in this case.

\subsection{Evidence from Political Contributions}

Does homeownership increase costly forms of participation beyond local politics? To answer this question, I estimate how property ownership influences a third form of participation: political contributions to candidates or committees for federal or state elections. These contributions represent a more costly form of participation than voting, but extend beyond local politics and into an individual's investment in federal and state elections. The outcome, Contributed $_{i t}$, is an indicator for whether individual $i$ made an itemized contribution in year $t{ }^{36}$ I restrict the sample to registered voters in the state prior to 2000 , the start of the

\footnotetext{
${ }^{35}$ This specification subsets to individuals in the voter file because date of birth is observed in the voter file but not in the property records.

${ }^{36} \mathrm{I}$ incorporate the merge uncertainty into this analysis in the same way mentioned for the analyses in Sections 4.1 and 4.2 .
} 
Table 4 - Effect of Homeownership on Political Contributions, 2000-2014.

\begin{tabular}{lcccc}
\hline \hline & \multicolumn{4}{c}{ Made Political Contribution $=1$} \\
& $(1)$ & $(2)$ & $(3)$ & $(4)$ \\
\hline Homeowner & 0.005 & 0.005 & 0.002 & 0.005 \\
& $(0.000)$ & $(0.000)$ & $(0.000)$ & $(0.000)$ \\
Observations & $11,826,502$ & $11,826,502$ & $7,028,296$ & $11,814,246$ \\
Outcome Mean & 0.007 & 0.007 & 0.009 & 0.007 \\
Individual FEs & Yes & Yes & Yes & Yes \\
Year-by-State FEs & Yes & No & No & No \\
Year-by-Zip Code FEs & No & Yes & No & No \\
Year-by-Value FEs & No & No & Yes & No \\
Year-by-Age FEs & No & No & No & Yes \\
\hline \hline
\end{tabular}

Robust standard errors clustered by individual in parentheses. All columns include only individuals who were registered to vote in the state prior to the start of the study period. Column 3 restricts the sample to those who become homeowners at some point during the study period.

panel. ${ }^{37}$ I do not review each particular estimate, but the motivation for each specification mirrors that in Table 3, which I discuss above.

Overall, two notable features stand out. First, across all specifications, homeownership leads to roughly a half percentage point in increase in the probability of making a contribution in a given year. Given that the baseline rate of donating is low, this represents nearly a $70 \%$ increase. Second, the point estimate in column 3, where I include year-by-home value decile fixed effects, reduces to a 0.2 percentage point increase. Because this specification computes homeowners' counterfactual trends using only individuals who would eventually go on to buy similarly priced homes but had not yet done so, this suggests we should be concerned that the effects reported in columns 1, 2, and 4 could be biased upward by changes in wealth, an important potential time-varying confounder. This would be plausible because the outcome variable itself requires monetary giving. Wealth and political contributions are positively correlated (Bonica and Rosenthal 2015), so we might expect this outcome to be especially vulnerable to pre-trending as a function of increased wealth. To check

\footnotetext{
${ }^{37}$ I show results using the full sample in Table A.14 in the Appendix, and the results are very similar.
} 
for possible pre-trending, in Figure A.8 in the Appendix I again model the dynamic effect of homeownership, using political contributions as the outcome variable. There is some evidence of pre-trending - the effect of homeownership in year $t$ on making a contribution in the year $t-1$ is positive and statistically significant, albeit small in magnitude. This is likely because increased wealth correlates both with the decision to purchase a home and the likelihood of making political contribution. Given that, we should prefer the more moderated effect in column 3, which makes comparisons among individuals with more similar levels of wealth. Nonetheless, the evidence suggests that becoming a property owner likely leads to an increase in donating to candidates for federal and state elections, on average.

\section{Homeowners and Renters Focus on Different Issues}

So far, I have shown that homeownership increases several forms of participation. But what motivates homeowners and renters to participate in local politics? And why does the gap in participation between homeowners and renters larger in Palo Alto than places like Dallas or Houston? One explanation is simply the parochial nature of small-scale democracy (Oliver, Ha, and Callen 2012). Homeowners might be less likely to show up to meetings in Dallas and Houston because those larger cities deal with a wider range of political issues in their local meetings compared to Palo Alto, where questions of land use and development tend to dominate the discussion. Understanding whether homeowners and renters are actually differentiated in the types of topics they raise in local meetings requires a design that holds time, place and the local meeting agenda fixed.

To do this, I use the text of each comment made by a member of the public at city council meetings in each of the three cities for which I have collected data. Each observation is a comment, which includes the full name, address, and statement that an individual makes in a meeting. Crucially, I also observe the date of the local meeting along with the individual's homeownership status at the time of the comment, so I can estimate which topics differentiate 
homeowners from renters within the same local meeting. I implement the linkage procedure described in Section 2.1.

The final dataset includes over 7,000 comments made by individuals at local city council meetings. ${ }^{38}$ To summarize the types of comments, I rely on a Structural Topic Model (STM) to model latent comment topics (Roberts, Stewart, and Tingley 2014). Similar to Latent Dirichlet Allocation (LDA) (e.g., Blei, Ng, and Jordan 2003), STM is a probabilistic topic model, which assigns each document a vector of weights over distinct topics. Its advantage for my particular context is that STM allows for the inclusion of comment-level covariate information, both to model the prevalence of topics as a function of observable characteristics and to conduct hypothesis testing about the relationships between document characteristics (like the homeownership status of a commenter) and topics that the model discovers (Roberts, Stewart, and Tingley 2014).

Figure 5 summarizes the top words in each of 10 topics discovered by the model, along with each topic's frequency. ${ }^{39}$ Because the frequency of topics likely varies both across cities and over time, I include indicators for each city-year in the model to allow time and place to affect the frequency with which a topic is discussed (Roberts, Stewart, and Tingley 2014). Some of the topics are more interpretable than others: the most frequent topic appears mainly procedural, where the most commonly used words include present, time, call, speak, and name. Other categories have more notable interpretations. Topic 1 appears related to housing and development, as it often uses words like home, house, property, and build. Topic 2 seems related to community programming and policing, commonly using words like

\footnotetext{
${ }^{38}$ I only include individuals that merge to the voter file in order to use only comments where the transcription of the name and address of the individual making the comment is of sufficiently high quality. Typographical errors in the meeting transcripts would lead to false negatives, meaning mistakenly coding individuals as non-homeowners when they are in fact homeowners, and lead to attenuation bias in estimated differences between homeowners and renters.

${ }^{39} \mathrm{I}$ use the stm package in $\mathrm{R}$, and I set the number of topics to 10 . I also run the same topic model 50 times with randomly sampled starting values, and in every case the top 7 words associated with each topic are the same. This suggests that the results are not sensitive to the starting values used in the topic estimation.
} 
Figure 5 - Topic Frequency in Public Statements at City Council Meetings. This graph summarizes the frequency of each of 10 topics discovered by the Structural Topic Model, with expected topic proportions on the x-axis. While some topics appear to be procedural $(6,7$, and 9), others appear related to policing (2), traffic (8), housing (1), and historic preservation (5).

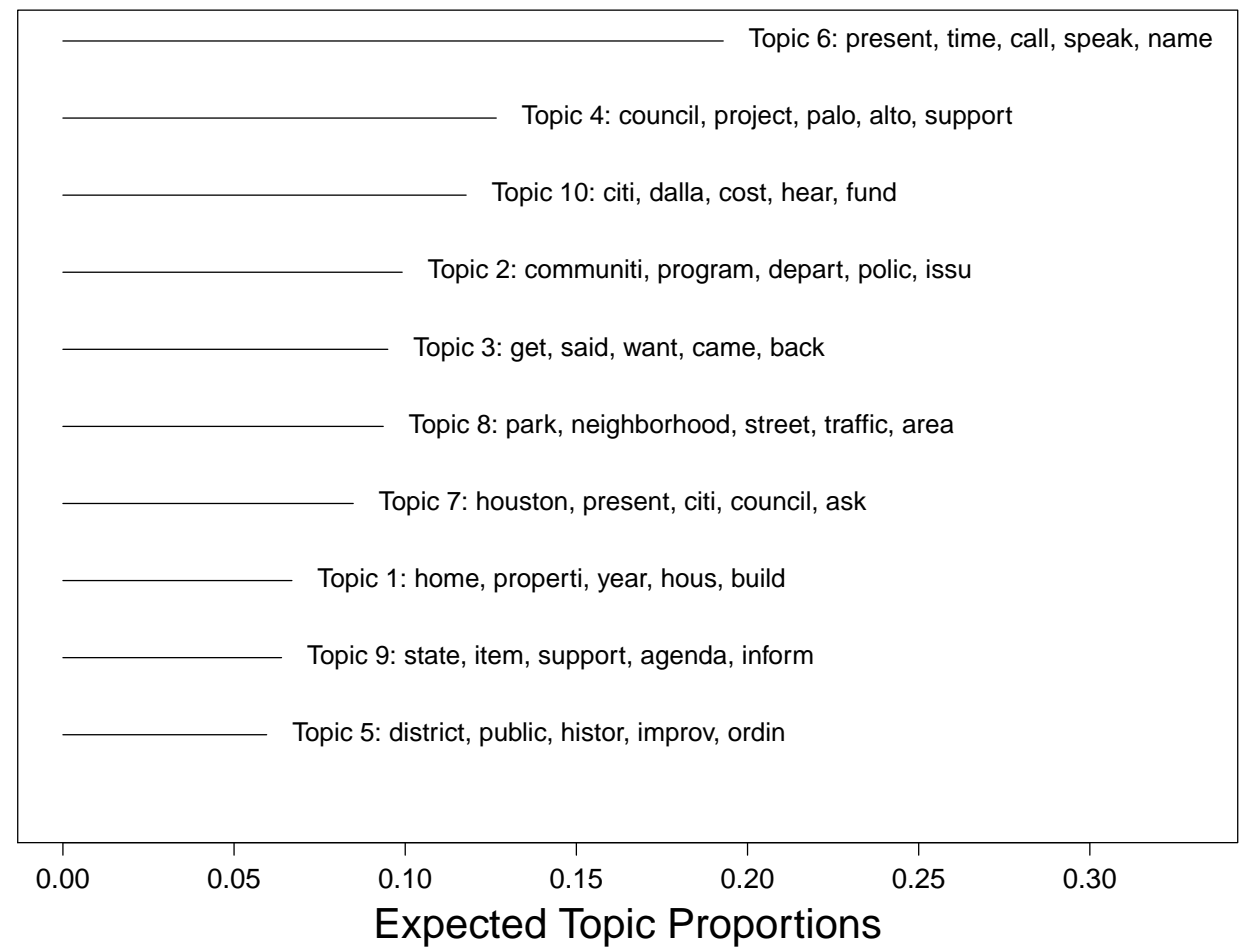

community, program, police, and department. Topic 8 seems to be about traffic, using words like parking, street, neighborhood, and traffic.

In Figure 6 I estimate how being a homeowner, as opposed to a renter, changes the proportion of the individual's comment we would expect to belong to each topic. For each topic, I regress the proportion of the document that falls in the topic on an indicator for whether the commenter is a homeowner along with city-year fixed effects, which control for unobservable factors that influence the frequency of topics in a city in a particular year. Consistent with expectations about the influence of homeowners in local politics (e.g., Fischel 2001; Einstein, Palmer, and Glick 2018b), I find that homeowners' comments are more likely to belong to topics that reference traffic, housing, property, and development. Meanwhile, renters are relatively more likely to comment on topics related to policing. While this evidence in purely 
Figure 6 - Change in Topic Proportion between Renters and Homeowners. This graph plots the change in the proportion of a comment that one would expect to belong to each topic for homeowners versus renters, with the change in proportion for going from a renter to a homeowner on the x-axis. The regressions include city-year fixed effects, which controls for unobservable characteristics of a city in a particular year that influence the frequency of each topic. Coefficients are plotted with $95 \%$ confidence intervals from robust standard errors. Homeowners are more likely to mention traffic, development, and historic, while renters are more likely to mention community, police, and department.

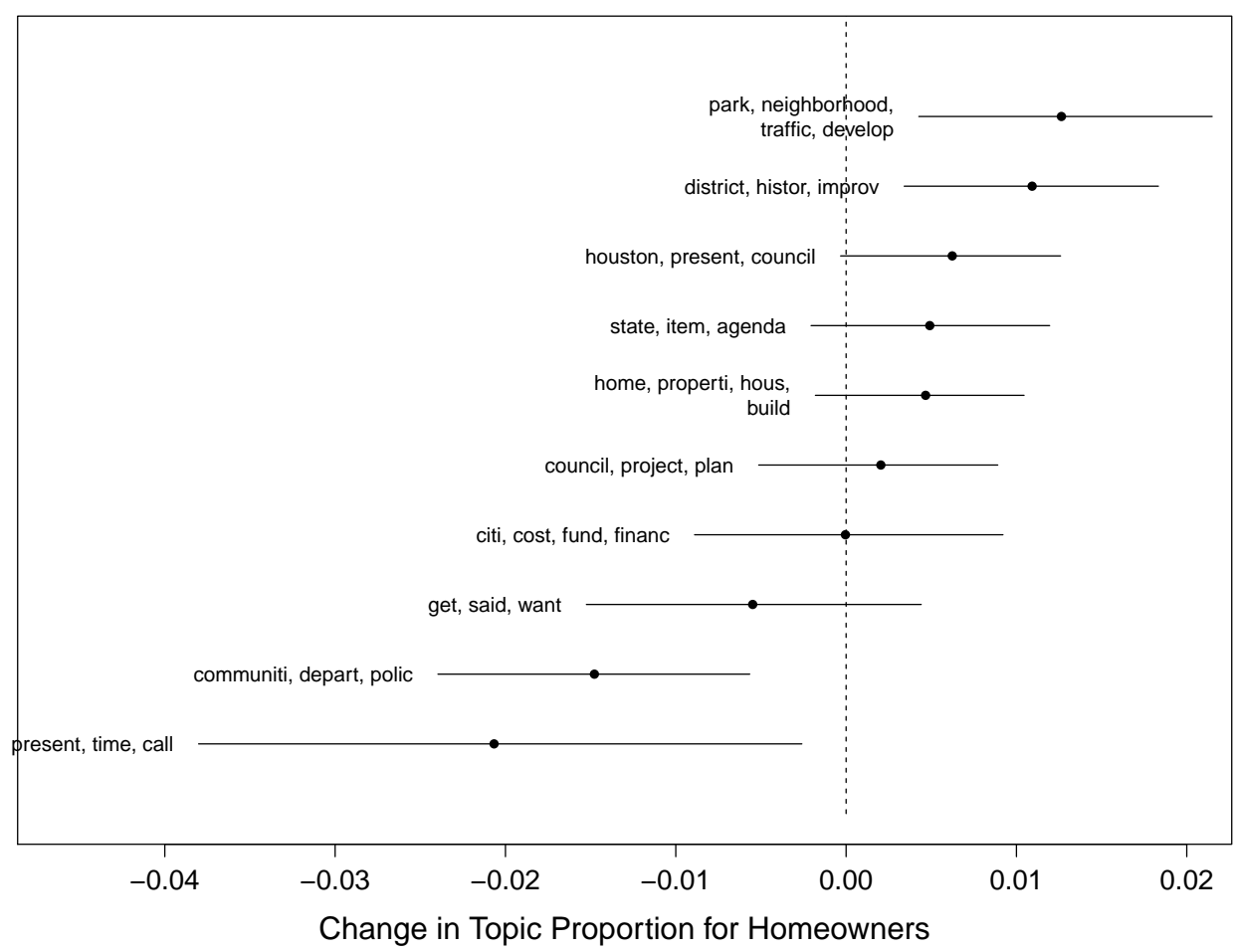

descriptive, it is consistent with the theory that homeowners are motivated to participate in local politics by different issues than are renters. Namely, homeowners are more likely to show up to comment about issues we might expect to relate to preserving their property values - that is, housing and development. Homeowners' disproportionate appeals to traffic and history are also consistent with qualitative accounts that show homeowners often raise concerns over traffic congestion, historical preservation, and environmental protection as justifications to restrict development (Gerber and Phillips 2003; Glaeser and Ward 2009).

One disadvantage of using STM is that the topics lack a direct interpretation. For a more directly interpretable summary of whether homeowners are more motivated to men- 
tion housing development at local meetings than renters, I code each comment according to whether the stems of any of the following words are used in the comment: build, character, development, environment, property, historical, history, home, homeowner, housing, neighborhood, traffic, and zoning. I choose these words because they are generally associated with concerns about housing development and with the reasons offered for supporting or opposing development projects (e.g., Gerber and Phillips 2003; Glaeser and Ward 2009; Einstein, Palmer, and Glick 2018b). Column 1 of Table 5 shows that homeowners are about 9.6 percentage points more likely to use at least one of these housing-related words in their comments compared to renters. To control for changes in the meeting agendas across cities and over time, columns 2 and 3 use city-year fixed effects and meeting fixed effects, which make comparisons between homeowners and renters within the same meeting year and at the same meeting, respectively. In column 3, for example, homeowners are about 7.9 percentage points more likely to use housing-related language than renters, even within the same meeting. This effect is reasonably precisely estimated: the $95 \%$ confidence interval spans from a 5.1 to 10.7 percentage point (or 17 to $35 \%$ ) increase in the likelihood of using housing-related langauge. Because these differences could be driven by the length of public comments, in columns 4-6 I also estimate the same regressions using a different outcome: the proportion of words in the comment that are any of the housing-related words mentioned above. These results again show that homeowners use language related to housing development more than renters, even when controlling for the city-year, the meeting agenda, and when normalizing by the length of comments.

While there are not enough repeat commenters who change homeownership status over the course of the panel to precisely estimate how becoming a homeowner changes the substance of an individual's comment, this section nonetheless shows that, descriptively, homeowners and renters focus on different issues in local meetings - even within the same meeting where the topics on the agenda are held fixed. 
Table 5 - Determinants of Using Housing-Related Language in Public Comments, 2000-2018.

\begin{tabular}{lccc|ccc}
\hline \hline & \multicolumn{3}{c}{ Used Housing Word $=1$} & \multicolumn{3}{c}{ Pct Words About Housing } \\
& $(1)$ & $(2)$ & $(3)$ & $(4)$ & $(5)$ & $(6)$ \\
\hline Homeowner & 0.096 & 0.084 & 0.079 & 0.006 & 0.012 & 0.010 \\
& $(0.012)$ & $(0.012)$ & $(0.014)$ & $(0.003)$ & $(0.003)$ & $(0.003)$ \\
Observations & 7,198 & 7,198 & 7,198 & 7,198 & 7,198 & 7,198 \\
Outcome Mean & 0.307 & 0.307 & 0.307 & 0.039 & 0.039 & 0.039 \\
City-Year FEs & No & Yes & No & No & Yes & No \\
Meeting FEs & No & No & Yes & No & No & Yes \\
\hline \hline
\end{tabular}

Robust standard errors clustered by meeting in parentheses. The unit of observation is a comment. The outcome in columns 1-3 is whether the commenter used stems of any of the following words in their statement: build, character, development, environment, property, historical, history, home, homeowner, housing, neighborhood, traffic, or zoning. The outcome in columns 4-6 is the share of words in each comment that were stems of these words.

\section{Conclusion}

Although there are well-established descriptive relationships between homeownership and political behavior, there is much less work on how the experience of becoming a homeowner changes individual political behavior. In this paper, I contribute to our understanding of how homeownership shapes behavior in three ways. First, using individual comments made by members of the public at local city council meetings, I document large inequalities in who participates in local politics. Individuals who show up and make statements at local meetings are overwhelmingly older, more likely to be male, and much more likely to participate in politics in other ways, like voting in local and national elections as well as making political contributions. Homeowners are drastically over-represented at local meetings in places where housing issues are particularly salient, like Palo Alto. Inequality in local political participation, therefore, is likely a function of the issues that are most salient in the local politics. 
Second, I present causal evidence that becoming a homeowner leads individuals to participate more in politics using three separate measures of participation: local meeting comments, voting in local elections, and making political contributions. While the mechanism for these increases is more difficult to pin down, the variation in the effects across geography again points to varying issue salience across different communities. Follow up analyses suggest that these effects likely cannot be wholly explained by wealth or changing adult roles. The economic incentives associated with property ownership appear to be an important motivator of political participation.

Lastly, I show that homeowners and renters seem to care about different topics in local political meetings, even within the same meeting where the agenda of topics are held fixed. Homeowners are more likely to raise topics related to housing development, consistent with the homevoter hypothesis, where homeowners become motivated to participate in local politics in order to protect their property value (Fischel 2001).

More broadly, housing policy has increasingly become a central focus of both local and national political discussion, which raises important and fundamental questions about how property ownership motivates and changes political behavior. ${ }^{40}$ With the proliferation of publicly available city council meeting minutes, along with more easily available administrative data at the individual level, researchers have new and exciting opportunities to advance our understanding of exactly how individuals map economic incentives onto their political behavior, both at the local and national level. This paper seeks to understand the political effects of effect these incentives for one of the most important financial changes in an individual's lifetime - becoming a property owner. Future work could link voters and property records to other types of administrative data, like marriage records, for example, to understand the role of other important influences on political behavior. Discussions in local city council meetings transcripts also present exciting opportunities to further document

\footnotetext{
${ }^{40}$ For a recent example of housing policy's importance in the national political discourse, see https://www . washingtonpost.com/business/2018/07/19/rents-soar-democrats-push-newpolicies-affordable-housing/?utm_term $=.46210 \mathrm{e} 1 \mathrm{c} 7 \mathrm{ec} 2$.
} 
and understand which local issues are most salient across both place and time, and how homeownership or other individual characteristics motivate participation in local politics. 


\section{References}

Acemoglu, Daron, and James A Robinson. 2005. Economic Origins of Dictatorship and Democracy. Cambridge University Press.

Angrist, Joshua D, and Jörn-Steffen Pischke. 2008. Mostly Harmless Econometrics: An Empiricist's Companion. Princeton University Press.

Ansolabehere, Stephen, and Eitan D Hersh. 2017. "ADGN: An Algorithm for Record Linkage Using Address, Date of Birth, Gender, and Name." Statistics and Public Policy 4(1): 1-10.

Ansolabehere, Stephen, John M De Figueiredo, and James M Jr. Snyder. 2003. "Why is There so Little Money in US Politics?" Journal of Economic Perspectives 17(1): 105-130.

Autor, David H. 2003. "Outsourcing at Will: The Contribution of Unjust Dismissal Doctrine to the Growth of Employment Outsourcing." Journal of Labor Economics 21(1): 1-42.

Blei, David M, Andrew Y Ng, and Michael I Jordan. 2003. "Latent Dirichlet Allocation." Journal of Machine Learning Research 3(Jan): 993-1022.

Bonica, Adam. 2014. "Mapping the Ideological Marketplace." American Journal of Political Science 58(2): 367-386.

Bonica, Adam. 2016. "Database on Ideology, Money in Politics, and Elections: Public version 2.0 [Computer file].".

Bonica, Adam, and Howard Rosenthal. 2015. "The Wealth Elasticity of Political Contributions by the Forbes 400.".

URL: https://papers.ssrn.com/sol3/papers.cfm?abstract ${ }_{i} d=2668780$

Brady, Henry E, Sidney Verba, and Kay Lehman Schlozman. 1995. "Beyond SES: A Resource Model of Political Participation." American Political Science Review 89(2): 271-294. 
Downs, Anthony. 1957. "An Economic Theory of Political Action in a Democracy." The Journal of Political Economy 65(2): 135-150.

Einstein, Katherine Levine, David M Glick, and Conor LeBlanc. 2017. "2016 Menino Survey of Mayors.".

URL: https://open.bu.edu/ds2/stream/?/documents/144518/page/1

Einstein, Katherine Levine, Maxwell Palmer, and David Glick. 2018a. "Racial Disparities in Housing Politics: Evidence from Administrative Data.".

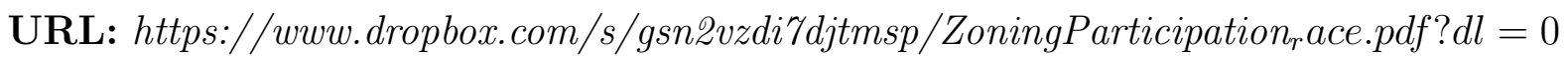

Einstein, Katherine Levine, Maxwell Palmer, and David M Glick. 2018b. "Who Participates in Local Government? Evidence from Meeting Minutes." Perspectives on Politics pp. 1-19.

Enamorado, Ted, Benjamin Fifield, and Kosuke Imai. 2019. "Using a Probabilistic Model to Assist Merging of Large-Scale Administrative Records." American Political Science Review 113(2): 353-371.

Engerman, Stanley L, and Kenneth L Sokoloff. 2005. "The Evolution of Suffrage Institutions in the New World." The Journal of Economic History 65(4): 891-921.

Fischel, William A. 2001. The Homevoter Hypothesis. Harvard University Press.

Fung, Archon. 2006. "Varieties of Participation in Complex Governance." Public Administration Review 66: 66-75.

Gay, Claudine. 2012. "Moving to Opportunity: The Political Effects of a Housing Mobility Experiment." Urban Affairs Review 48(2): 147-179.

Gerber, Alan S, Donald P Green, and Christopher W Larimer. 2008. "Social Pressure and Voter Turnout: Evidence from a Large-Scale Field Experiment." American Political Science Review 102(1): 33-48. 
Gerber, Elisabeth R, and Justin H Phillips. 2003. "Development Ballot Measures, Interest Group Endorsements, and the Political Geography of Growth Preferences." American Journal of Political Science 47(4): 625-639.

Glaeser, Edward, and Joseph Gyourko. 2018. "The Economic Implications of Housing Supply." Journal of Economic Perspectives 32(February): 3-30.

URL: http://www.aeaweb.org/articles?id=10.1257/jep.32.1.3

Glaeser, Edward L, and Bryce A Ward. 2009. "The Causes and Consequences of Land Use Regulation: Evidence from Greater Boston." Journal of Urban Economics 65(3): 265-278.

Goodman-Bacon, Andrew. 2018. Difference-in-Differences with Variation in Treatment Timing. Technical report National Bureau of Economic Research.

Green, Donald P, Alan S Gerber, and David W Nickerson. 2003. "Getting Out the Vote in Local Elections: Results from Six Door-to-Door Canvassing Experiments." Journal of Politics 65(4): 1083-1096.

Hall, Andrew B, and Jesse Yoder. 2018. "Does Homeownership Influence Political Behavior? Evidence from Administrative Data.".

URL: http://www.andrewbenjaminhall.com/homeowner.pdf

Hankinson, Michael. 2018. "When Do Renters Behave Like Homeowners? High Rent, Price Anxiety, and NIMBYism." American Political Science Review 112(3): 473 - 493.

Highton, Benjamin. 2004. "Voter Registration and Turnout in the United States." Perspectives on Politics 2(3): 507-515.

Highton, Benjamin, and Raymond E Wolfinger. 2001. "The First Seven Years of the Political Life Cycle." American Journal of Political Science pp. 202-209. 
Imai, Kosuke, and In Song Kim. 2020. "On the Use of Two-way Fixed Effects Regression Models for Causal Inference with Panel Data." Working Paper .

URL: https://imai.fas.harvard.edu/research/files/FEmatch-twoway.pdf

Jha, Saumitra, and Moses Shayo. 2019. "Valuing Peace: The Effects of Financial Market Exposure on Votes and Political Attitudes." Econometrica Forthcoming.

URL: https://ssrn.com/abstract=2716660

Kim, Seo-young Silvia. 2019. "Getting Settled in Your New Home: The Costs of Moving on Voter Turnout." Working Paper .

URL: https://sysilviakim.com/research/

Marble, William, and Clayton Nall. 2018. "Where Self-Interest Trumps Ideology: Liberal Homeowners and Local Opposition to Housing Development.".

URL: https://www.dropbox.com/s/0cpefxjmqhrgkqg/interest ${ }_{35} . p d f ? d l=0$

McCabe, Brian J. 2016. No Place Like Home: Wealth, Community, and the Politics of Homeownership. Oxford University Press.

Meltzer, Allan H, and Scott F Richard. 1981. "A Rational Theory of the Size of Government." Journal of Political Economy 89(5): 914-927.

Oliver, J Eric, and Shang E Ha. 2007. "Vote Choice in Suburban Elections." American Political Science Review 101(3): 393-408.

Oliver, J Eric, Shang E Ha, and Zachary Callen. 2012. Local Elections and the Politics of Small-Scale Democracy. Princeton University Press.

Riker, William H, and Peter C Ordeshook. 1968. "A Theory of the Calculus of Voting." American Political Science Review 62(1): 25-42.

Roberts, Margaret E, Brandon M Stewart, and Dustin Tingley. 2014. "stm: R Package for Structural Topic Models." Journal of Statistical Software VV(II): 12. 
Squire, Peverill, Raymond E Wolfinger, and David P Glass. 1987. "Residential Mobility and Voter Turnout." American Political Science Review 81(1): 45-65.

Trounstine, Jessica. 2018. "The Geography of Inequality: How Land Use Regulation Produces Segregation and Polarization.".

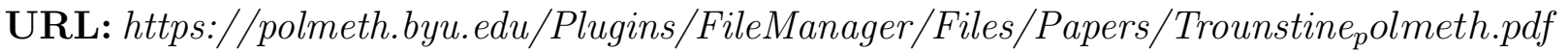

Verba, Sidney, Kay Lehman Schlozman, and Henry E Brady. 1995. Voice and Equality: Civic Voluntarism in American Politics. Harvard University Press.

Wong, Weihuang. 2018. "Our Town: Support for Housing Growth When Localism Meets Liberalism.".

URL: https://papers.ssrn.com/sol3/papers.cfm?abstract ${ }_{i} d=3173813$ 


\section{Online Appendix}

Intended for online publication only.

\section{Contents}

A.1 Details of the Record Linkage Procedure . . . . . . . . . . . . . . . . . 2

A.2 Evaluating the Commenter Merge Rate Over Time by City . . . . . . . . 5

A.3 Local Meeting Participants In Houston . . . . . . . . . . . . . 6

A.4 Local Meeting Participants, Descriptive Differences . . . . . . . . . . . 8

A.5 Local Meeting Participants, Descriptive Differences for Recent Years Only . 11

A.6 Local Election Turnout Over Time Across Sample Cities . . . . . . . . . . . 13

A.7 Validating the Parallel Trends Assumption . . . . . . . . . . . . . . . . . 14

A.8 Estimating the Effect of Homeownership on Commenting Across Home Value 20

A.9 Alternative Multi-Period Difference-in-Differences Estimator . . . . . . . . . 22

A.10 Estimating the Effect of Homeownership Across Urban and Rural Settings . 23

A.11 Estimating the Effect of Homeownership Across Property Type . . . . . . . 24

A.12 Estimating the Effect of Homeownership on Local Turnout for Recent Years 26

A.13 Additional Results for Comments in City Council Meetings . . . . . . . . . 27

A.14 Additional Results for Local Turnout . . . . . . . . . . . . . . . . 28

A.15 Additional Results for Contributions . . . . . . . . . . . . . . . 30

A.16 Topic Model . . . . . . . . . . . . . . . . . . . . . 32 


\section{A.1 Details of the Record Linkage Procedure}

In this section, I describe the record linkage procedure in detail. This section is intended to provide details on the record linkage procedure both for replicability and to provide a guideline for future scholars wishing to carry out a similar record linkage task using large, administrative datasets, which has become increasingly common in political science.

I link individuals across 4 administrative datasets using the full name and address of individuals: (1) voter files from the entire states of California and Texas, provided by voter file vendor L2, (2) property records, provided by private data vendor CoreLogic, (3) individual political contribution records, from the Database on Ideology, Money in Politics, and Elections (DIME) (Bonica 2014, 2016), and (4) an original dataset of public statements made by individuals in city council meetings in Palo Alto, CA (2002-2010), Dallas, TX (2000-2018), and Houston, TX (2004-2014).

To link these datasets, I begin with the full voter file for the states of California and Texas. I use the voter file current as of September 2018 for each state. For each individual, the file contains full name and address, registration date, date of birth, gender, party affiliation, and turnout history in local and national elections from 2000-2017.

I link the voter file with property tax and deed records for the entire states of California and Texas. The property records include the full name of each property's owner(s), address, property type, sale date, sale price, assessed value, and other information. To pre-process the property records, I subset to owners of the following property types: single family residence, condominium, duplex, and apartment. If properties have two owners, I treat each owner as a unique record for the purposes of the merge.

Because there is no unique identifier for any individual that is common across each of the datasets, I must link individuals on other attributes that are available in each dataset. Specifically, the voter file and property records both contain each individual's last name, first name, zip code, and full street address.

Following recent work in political science on merging individuals across large-scale administrative datasets, I use the fastLink package in R (Enamorado, Fifield, and Imai 2019) to implement this merge. I choose to use fastLink because it has several appealing properties for the task at hand. First, fastLink implements a probabilistic, as opposed to a deterministic, linkage procedure. Deterministic procedures are appealing when there is a unique identifier across datasets, but probabilistic procedures can accommodate variation in how individuals' names and addresses are recorded across different datasets. Second, it can accommodate the presence of missing data. Third, it is possible to generate estimates of the false positive and false negative rates, which are not possible using deterministic linkage

procedures. Fourth, it enables the researcher to incorporate the uncertainty inherent in the merge process into the post-merge estimation. Finally, and perhaps more prosaically, it limits arbitrary decisions from the researcher about what features must be sufficiently similar in order to declare two records a match.

There are two possible types of errors when linking two records. The first is a false positive, where two records are linked but actually correspond to different individuals, and the second is a false negative, where two individuals are not linked but actually correspond to the same individual. Using probabilistic linking presents a trade-off: while deterministic procedures limit the potential for false positives, they sacrifice in terms of the merge rate 
and false negative rate because they require exact matches on all variables used in the merge. Probabilistic procedures increase the number of potential matches and bring down the false negative rate - at the risk of increasing the number of false positives. Because the false positive rate is often low when linking large administrative datasets with a lot of information (full name and address), I opt to use the probabilistic procedure in order to increase the match rate and decrease the rate of false negatives.

Because each of the datasets contain millions of records, I first block on zip code, and then proceed by matching probabilistically on last name, first name, and full street address. Specifically, for the approximate string matching I use the Jaro-Winkler distance to measure string similarity, setting the Jaro-Winkler penalty parameter $p$ equal to 0.1 . I also enforce one-to-one matching, ensuring that each observation in the voter file is at most matched to one observation in the property records. I set "linprog.dedupe = TRUE" in fastLink in order to use Winkler's linear programming solution to enforce one-to-one matching. Using this procedure, each of the best matches is assigned a posterior probability of being a match, and I choose the recommended threshold of 0.85 to declare two records a match (Enamorado, Fifield, and Imai 2019). In order to incorporate the merge uncertainty into the post-merge estimation - following Enamorado, Fifield, and Imai (2019) - for treated units (homeowners) I use the match probability from this linking procedure as the homeownership treatment variable.

Overall, many individuals in the voter file are identified as homeowners: $55.91 \%$ of individuals in the voter file are homeowners based on this linkage procedure. The merge rates in California and Texas are $50.44 \%$ and $60.49 \%$, respectively, which are roughly consistent with each state's homeownership rate from the US Census (https://www.latticepublishing. $\mathrm{com} / \mathrm{blog} /$ states-with-the-highest-homeownership-rates). As noted above, one of the advantages of using this probabilistic linking procedure is that it is possible to generate estimates of the false positive and false negative rates. Overall, the estimated false positive rate, where two records are linked but correspond to two different individuals, is $0.52 \%(0.28 \%$ for California and $0.73 \%$ for Texas). The estimated false negative rate, where two records are not linked but correspond to the same individual, is $13.4 \%$ (14.3\% for California and $12.6 \%$ for Texas).

I preserve both unmatched voter file records and unmatched property records for subsequent merges. This means that individuals in the voter file who do not match to the property records using this procedure are coded as non-homeowners, and homeowners who do not match to the voter file are included and coded as non-voters. To the extent that there are false negatives - or "spillover" between the treatment and control group, where individuals who become homeowners are coded as renters - this would bias effects of becoming a homeowner toward zero.

Next, I merge in political contribution records for the entire states of California and Texas for each year from 2000 through 2014. These records contain itemized political contributions to candidates or committees for federal and state offices. Federal races include Presidential, US House, and US Senate races, while state races include elections for Governor and state legislature. Because the contributions data contains much of the same information as the voter file and property records, namely zip code, last name, first name, and self-reported address, I use the same probabilistic linkage procedure as the one described for linking the voter file to property records. I select the best match using this procedure. This outputs the 
full population of registered voters and property owners, but now includes information on whether the individual made a contribution in each year from 2000 through 2014, coded as a 0 if I fail to find a contribution record for that individual. I again preserve any individual in the voter file or in the property records for the subsequent merge. The false positive rate is $3.0 \%$ (2.3\% in California and $3.7 \%$ in Texas), while the false negative rate is $29.0 \%$ (25.5\% in California and $32.2 \%$ in Texas). The false negative rate is slightly higher than that from merging the voter file to the property records, likely because the contribution records rely on self-reported address.

Finally, I link individuals to an original dataset on public participation in local city council meetings. Each observation in the meetings data is a comment, accompanied by the individual's full name, address, zip code, and date of the local meeting. I first pre-process the meetings data by collapsing the dataset so that the unit is a individual, and I generate a count of the total number of comments an individual makes in each year, so that the unit of analysis is an individual. Each observation, therefore, contains the first and last name as well as full address for each unique commenter in each city. Pooling all three cities together, about $0.27 \%$ of residents make a comment at a local city council meeting at some point during the study period. This rate is higher in Palo Alto (1.78\%) compared to Dallas $(0.29 \%)$ and Houston $(0.21 \%)$.

I again rely on fastLink to carry out this last merge, which joins 1) individuals in the voter file and property records to 2) commenters in local meetings. I do this separately for each of the three cities, matching on last name, first name, address, and zip code. Because zip code is available for the city council meeting transcripts in Houston, but only name and address are available in the Dallas and Palo Alto meeting transcripts, I block on zip code for the city of Houston but search the entire cities for Dallas and Palo Alto. Similar to the previous linkage procedures, for the approximate string matching I use the Jaro-Winkler distance, setting the penalty parameter $p$ equal to 0.1 . I enforce one-to-one matching and declare two records to be a match if the posterior probability of being a match is above the 0.85 threshold. For each of the three cities, I code an individual-year as a 0 for having commented if I do not find a match for that individual in the local meetings data.

The final dataset includes over 3.5 million unique individuals in California and Texas, and I observe each individual's full name and full address. For individuals in the voter file, I observe their date of birth, gender, and voting history since 2000. For individuals in the property records, I observe the sale date of the property they own, the property type, and the assessed value of the property. For individuals in DIME contributions data, I observe the individual's contribution amount in each year from 2000 to 2014, along with the amount the individual donates to various types of candidates or committees. For individuals in the local meetings data for Palo Alto, Dallas, and Houston, I observe whether or not an individual made a public comment, along with the topic and, in many cases, the full text of their statement. 


\section{A.2 Evaluating the Commenter Merge Rate Over Time by City}

In this section, I evaluate the rate at which commenters in local city council meetings merge to the joint voter file and property records data. In Figure A.1 I show this rate over time for each of the cities in my sample. Overall, the merge rates are quite high: over $85 \%$ of commenters in Dallas are linked to the voter file and property records data, while over $90 \%$ of commenters in Houston and Palo Alto are linked to the voter file and property records data. The merge rates are similar over time for each of the cities.

Figure A.1 - Comment Merge Rate Across Sample Cities

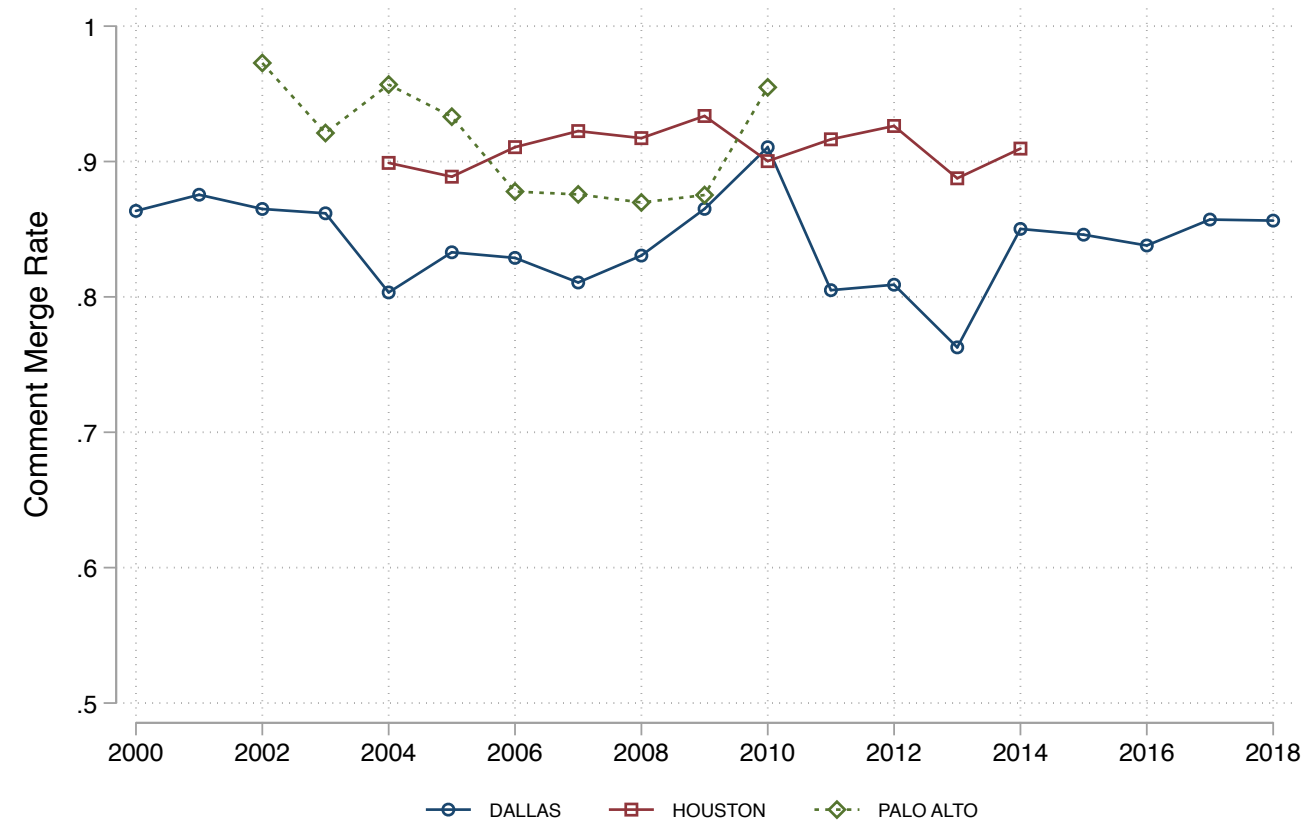

Note: Comment merge rate is shown for each city in the sample. Palo Alto is shown in green points marked by diamonds, Houston is shown in red squares, and Dallas is shown in blue circles. 


\section{A.3 Local Meeting Participants In Houston}

In this section, I show descriptive characteristics of local meeting participants in Houston, Texas from 2004-2014.

Figure A.2 - Houston City Council Commenters, 2004-2014. Commenters are shown in blue, while non-commenters are shown in gray. The unit of observation is a person-year. Registration year, birth year, female, and party registration are only available for individuals in the voter file. The logged contributions graph conditions on person-years in which a donation was made.
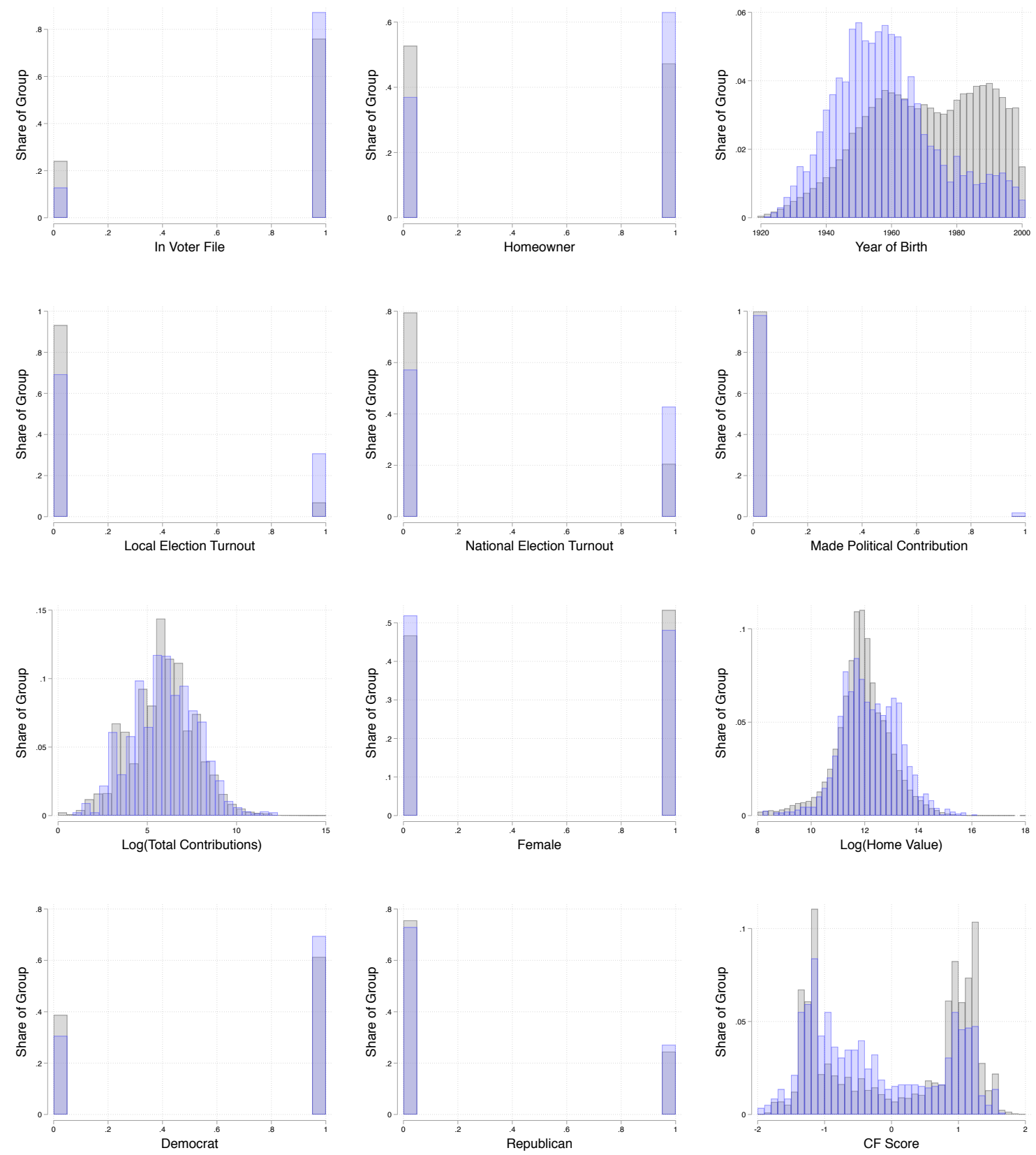
Histograms of individuals who show up to local city council meetings to make a public comment are shown in blue, while histograms of those who do not participate in local meetings are shown in gray. Many of the differences between between commenters and noncommenters resemble those found in Dallas in Figure 3. Notably, local meeting participants in Houston are more likely to be registered to vote, homeowners, older, male, wealthier, voters in local and national elections, and political donors, on average. 


\section{A.4 Local Meeting Participants, Descriptive Differences}

In this section, I provide formal tables characterizing the differences between those who participate in local city council meetings and those who do not, shown separately for each city in the sample. In Table A.1, I show differences in means between commenters (column 1) and non-commenters (column 2) for a variety of attributes in Palo Alto. Column 3 shows the difference between column 1 and column 2, and column 4 shows the total number of person-year observations for each attribute. In Palo Alto, those who comment at local city council meetings are 12 percentage points more likely to be registered to vote, 21 percentage points more likely to be homeowners, and about 15 years older than non-commenters, on average. Commenters also participate in local and national elections, donate, and register with a political party at much higher rates than non-commenters, on average. Because the sample size is large, all t-tests for differences in means are significant at the $\alpha=0.01$ significance level for each attribute. Overall, this table shows the results from Figure 2 more formally, and illustrates large differences between commenters and non-commenters in local city council meetings in Palo Alto.

Table A.1 - Descriptive Statistics, Palo Alto City Council Commenters, 2002-2010.

\begin{tabular}{lcccc}
\hline \hline & $\begin{array}{c}\text { Mean } \\
\text { Commenters } \\
(1)\end{array}$ & $\begin{array}{c}\text { Mean } \\
\text { Non-Commenters }\end{array}$ & Difference & Observations \\
& 0.89 & $(2)$ & $(3)$ & $(4)$ \\
\hline In Voter File & 0.62 & 0.77 & 0.12 & 589,545 \\
Homeowner & 1953 & 0.42 & 0.21 & 589,545 \\
Birth Year & 1990 & 2002 & -15.11 & 455,976 \\
Registration Year & 0.71 & 0.24 & -11.57 & 456,516 \\
Local Election Turnout & 0.83 & 0.43 & 0.47 & 202,896 \\
National Election Turnout & 0.112 & 0.013 & 0.099 & 253,620 \\
Donor & 364.04 & 49.90 & 314.14 & 589,545 \\
Donation Amount & 0.49 & 0.52 & -0.03 & 447,545 \\
Female & 0.66 & 0.55 & 0.11 & 456,516 \\
Democrat & 0.14 & 0.11 & 0.03 & 456,516 \\
Republican & -0.87 & -0.85 & -0.02 & 7,567 \\
CF Score & 764,750 & 1076325 & $-311,575$ & 299,880 \\
Home Value & (n) & & & \\
\hline \hline
\end{tabular}

Note: This table presents descriptive statistics for the merged dataset on voters and homeowners in Palo Alto. Column 1 presents means for individuals who make a comment at a local meeting at some point during the length of the panel. Column 2 shows means for individuals who do not make a comment at a city council meeting at any point during the length of the panel. Column 3 computes the difference in means between commenters and non-commenters. Because of the large number of observations, t-tests for difference in means are all significant at the $\alpha=0.01$ level. Registration year, birth year, female, and party registration are only available for individuals in the voter file. I impute 0 for local turnout and national turnout if the individual does not merge to the voter file, and I impute 0 for donor and donation amount if the individual does not merge to FEC donation records.

Table A.2 shows descriptive differences between commenters and non-commenters for the city of Dallas. The table mirrors that of Table A.1, where column 1 shows the mean for those who participate in local meetings, column 2 shows the mean for those who do not participate, 
column 3 shows the difference in means, and column 4 shows the total number of personyears. In Dallas, those who comment at local city council meetings are 9 percentage points more likely to be registered to vote, 10 percentage points more likely to be homeowners, and about 11.5 years older than non-commenters, on average. Like in Palo Alto, commenters also participate in local and national elections, donate, and register with a political party at higher rates than non-commenters, on average. All t-tests for differences in means are significant at the $\alpha=0.01$ significance level for each attribute. Overall, this table shows that there are large differences between commenters and non-commenters in Dallas, although these differences are smaller than many of those in Palo Alto.

\section{Table A.2 - Descriptive Statistics, Dallas City Council Com- menters, 2000-2018.}

\begin{tabular}{lcccc}
\hline \hline & $\begin{array}{c}\text { Mean } \\
\text { Commenters }\end{array}$ & $\begin{array}{c}\text { Mean } \\
\text { Non-Commenters }\end{array}$ & Difference & Observations \\
& $(1)$ & $(2)$ & $(3)$ & $(4)$ \\
\hline In Voter File & 0.87 & 0.78 & 0.09 & $14,058,290$ \\
Homeowner & 0.49 & 0.39 & 0.10 & $14,058,290$ \\
Birth Year & 1958 & 1969 & -11.60 & $10,897,735$ \\
Registration Year & 1992 & 2003 & -10.74 & $10,903,435$ \\
Local Election Turnout & 0.32 & 0.07 & 0.25 & $4,017,055$ \\
National Election Turnout & 0.63 & 0.33 & 0.30 & $5,164,785$ \\
Donor & 0.024 & 0.003 & 0.021 & $14,058,290$ \\
Donation Amount & 75.07 & 10.53 & 64.54 & $14,058,290$ \\
Female & 0.47 & 0.53 & -0.06 & $10,895,341$ \\
Democrat & 0.70 & 0.64 & 0.06 & $10,903,435$ \\
Republican & 0.27 & 0.25 & 0.03 & $10,903,435$ \\
CF Score & -0.30 & 0.04 & -0.34 & 33,665 \\
Home Value & 463,548 & 324,781 & 138,767 & $6,667,423$ \\
\hline \hline
\end{tabular}

Note: This table presents descriptive statistics for the merged dataset on voters and homeowners in Dallas. Column 1 presents means for individuals who make a comment at a local meeting at some point during the length of the panel. Column 2 shows means for individuals who do not make a comment at a city council meeting at any point during the length of the panel. Column 3 computes the difference in means between commenters and non-commenters. Because of the large number of observations, t-tests for difference in means are all significant at the $\alpha=0.01$ level. Registration year, birth year, female, and party registration are only available for individuals in the voter file. I impute 0 for local turnout and national turnout if the individual does not merge to the voter file, and I impute 0 for donor and donation amount if the individual does not merge to FEC donation records.

Finally, Table A.3 shows descriptive differences between commenters and non-commenters for the city of Houston. The table follows the same format as Tables A.1 and A.2. For brevity, I do not review each particular difference, but overall the results for Houston are quite similar to those in Dallas. 
Table A.3 - Descriptive Statistics, Houston City Council Commenters, 2004-2014.

\begin{tabular}{lcccc}
\hline \hline & $\begin{array}{c}\text { Mean } \\
\text { Commenters } \\
(1)\end{array}$ & $\begin{array}{c}\text { Mean } \\
\text { Non-Commenters }\end{array}$ & Difference & Observations \\
& $(1)$ & $(3)$ & $(4)$ \\
\hline In Voter File & 0.87 & 0.76 & 0.11 & $18,723,386$ \\
Homeowner & 0.63 & 0.47 & 0.16 & $18,723,386$ \\
Birth Year & 1957 & 1969 & -11.89 & $14,220,030$ \\
Registration Year & 1992 & 2003 & -10.73 & $14,226,564$ \\
Local Election Turnout & 0.49 & 0.11 & 0.38 & $3,879,972$ \\
National Election Turnout & 0.60 & 0.31 & 0.29 & $7,759,944$ \\
Donor & 0.033 & 0.003 & 0.030 & $18,723,386$ \\
Donation Amount & 1152.91 & 7.35 & 1145.56 & $18,723,386$ \\
Female & 0.48 & 0.53 & -0.05 & $14,209,580$ \\
Democrat & 0.69 & 0.61 & 0.08 & $14,226,564$ \\
Republican & 0.27 & 0.24 & 0.03 & $14,226,564$ \\
CF Score & -0.38 & -0.01 & -0.37 & 53,382 \\
Home Value & 362,350 & 250,902 & 111,447 & $9,666,129$ \\
\hline \hline
\end{tabular}

Note: This table presents descriptive statistics for the merged dataset on voters and homeowners in Houston. Column 1 presents means for individuals who make a comment at a local meeting at some point during the length of the panel. Column 2 shows means for individuals who do not make a comment at a city council meeting at any point during the length of the panel. Column 3 computes the difference in means between commenters and non-commenters. Because of the large number of observations, t-tests for difference in means are all significant at the $\alpha=0.01$ level. Registration year, birth year, female, and party registration are only available for individuals in the voter file. I impute 0 for local turnout and national turnout if the individual does not merge to the voter file, and I impute 0 for donor and donation amount if the individual does not merge to FEC donation records. 


\section{A.5 Local Meeting Participants, Descriptive Differences for Recent Years Only}

In this section, I show descriptive differences between commenters and non-commenters in Dallas using only recent years, 2014-2018. One drawback of the datasets is that I have local meetings data for varying time windows (2002-2010 for Palo Alto, 2000-2018 for Dallas, and 2004-2014 for Houston), but I only observe the California and Texas voter files in 2018. The composition of voter files changes over time - new voters register, others become inactive or purged from the voter file entirely, and so on. If, for example, commenters are more likely to remain in the voter file over time compared to non-commenters, this would bias the differences that I compute on attributes like local turnout, national turnout, age, and other attributes in the voter file. It is likely that commenters are more likely to remain in the voter file over time and be observed in my dataset in 2018: commenters are more likely to be homeowners, older, and regular participants in elections, which are all characteristics that are likely positively correlated with remaining in the voter file at the same address for a longer period of time.

To mitigate this potential source of bias as much as possible, I investigate whether the differences between commenters and non-commenters are similar using only years that are close to when the voter file data is available. Specifically, in Table A.4 I compute differences between commenters and non-commenters in Dallas, subsetting to the years 2014-2018. Comparing Table A.4 to Table A.2, which uses the full time series of local meetings in Dallas, the differences for each attribute remain very similar. This is reassuring evidence that the bias outlined above is likely not large enough to substantially alter the conclusions in Section 3. 


\section{Table A.4 - Descriptive Statistics, Dallas City Council Com- menters, 2014-2018.}

\begin{tabular}{|c|c|c|c|c|}
\hline & $\begin{array}{c}\text { Mean } \\
\text { Commenters } \\
(1)\end{array}$ & $\begin{array}{c}\text { Mean } \\
\text { Non-Commenters } \\
(2)\end{array}$ & $\begin{array}{c}\text { Difference } \\
\text { (3) }\end{array}$ & $\begin{array}{c}\text { Observations } \\
\text { (4) }\end{array}$ \\
\hline In Voter File & 0.91 & 0.78 & 0.13 & $3,699,550$ \\
\hline Homeowner & 0.47 & 0.39 & 0.07 & $3,699,550$ \\
\hline Birth Year & 1963 & 1969 & -6.72 & $2,867,825$ \\
\hline Registration Year & 1997 & 2003 & -6.27 & $2,869,325$ \\
\hline Local Election Turnout & 0.44 & 0.10 & 0.34 & $1,147,730$ \\
\hline National Election Turnout & 0.78 & 0.46 & 0.32 & $1,147,730$ \\
\hline Donor & 0.009 & 0.001 & 0.007 & $3,699,550$ \\
\hline Donation Amount & 22.78 & 3.71 & 19.07 & $3,699,550$ \\
\hline Female & 0.46 & 0.53 & -0.07 & $2,867,195$ \\
\hline Democrat & 0.69 & 0.64 & 0.05 & $2,869,325$ \\
\hline Republican & 0.26 & 0.25 & 0.01 & $2,869,325$ \\
\hline CF Score & -0.48 & -0.34 & -0.13 & 4,086 \\
\hline Home Value & 420,946 & 325,154 & 95,792 & $1,754,585$ \\
\hline
\end{tabular}

Note: This table presents descriptive statistics for the merged dataset on voters and homeowners in Dallas. Column 1 presents means for individuals who make a comment at a local meeting at some point during the length of the panel. Column 2 shows means for individuals who do not make a comment at a city council meeting at any point during the length of the panel. Column 3 computes the difference in means between commenters and non-commenters. Because of the large number of observations, t-tests for difference in means are all significant at the $\alpha=0.01$ level. Registration year, birth year, female, and party registration are only available for individuals in the voter file. I impute 0 for local turnout and national turnout if the individual does not merge to the voter file, and I impute 0 for donor and donation amount if the individual does not merge to FEC donation records. 


\section{A.6 Local Election Turnout Over Time Across Sample Cities}

In this section, I show the overall turnout rate in local elections for each of the cities in the sample. For each of the cities, I compute the average turnout rate in odd-year elections for which a) a city-wide local election was held, and b) I have data on comments in local meetings for that city (2002-2010 for Palo Alto, 2000-2018 for Dallas, and 2004-2014 for Houston). For each of the cities, I include both registered voters and non-registered homeowners in the sample to compute the local election turnout rate. The turnout rate varies across cities, with the highest local election turnout in Palo Alto, shown in green, followed by Houston, in red, and Dallas, in blue.

\section{Figure A.3 - Local Election Turnout Rate Across Sample Cities}

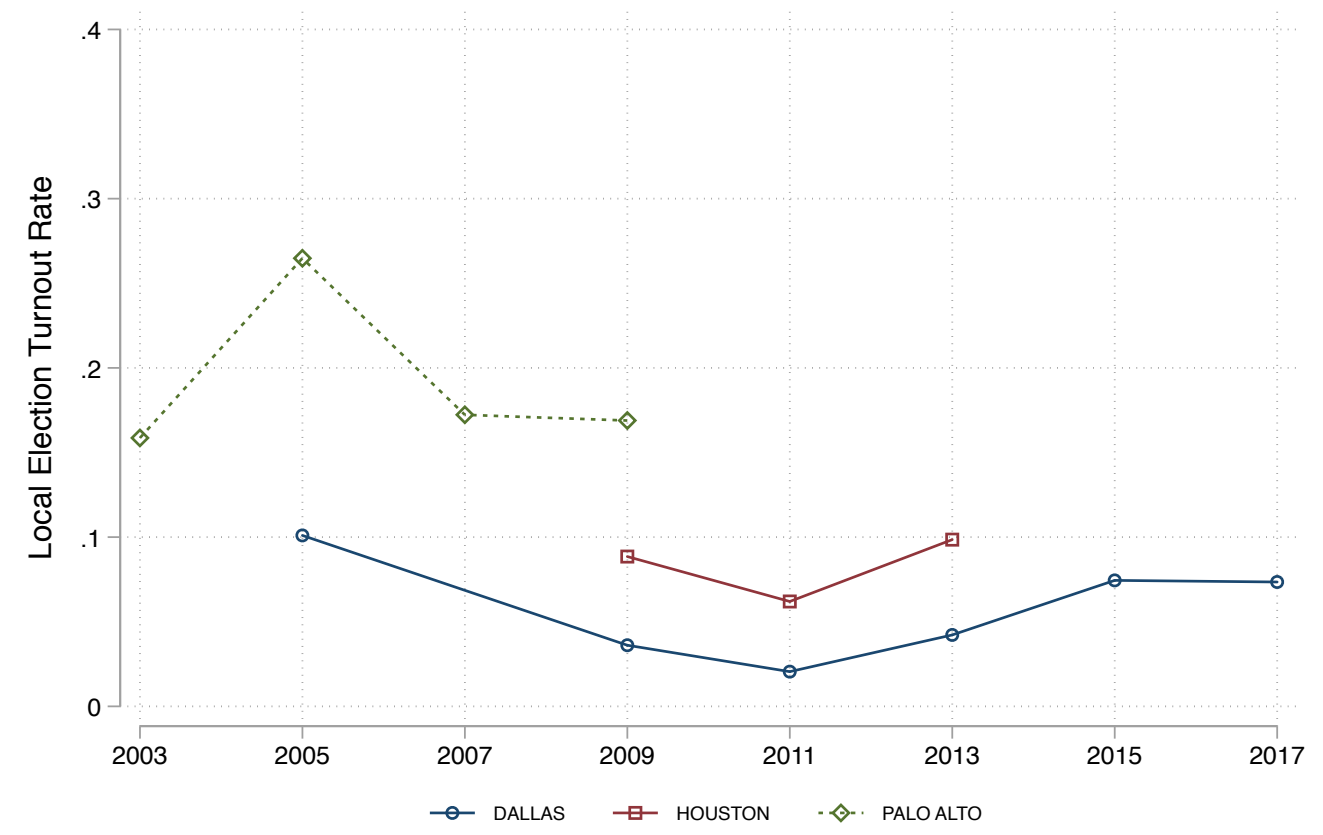

Note: Local election turnout rate is shown for each city in the sample, and for which a) an odd-year, city-wide local election was held, and b) I have data on comments in local city council meetings for that city and year. Palo Alto is shown in green points marked by diamonds, Houston is shown in red squares, and Dallas is shown in blue circles. 


\section{A.7 Validating the Parallel Trends Assumption}

In this section, I take a few different approaches to help validate the parallel trends assumption.

First, in Table A.5 I include leads of the homeowner variable, where an individual is coded as a 1 for homeowner in time $t+1$ if they are not a homeowner in a given year, but will become a homeowner in the following period. If the effect of homeownership on political participation is not the result of pre-trending, we would expect that the coefficient on the lead variable to be close to zero. In columns 1, 3, and 5, I include a homeownership lead variable for each of the three outcomes in the main body of the paper. In each case, the main effect of homeownership remains similar, while the coefficients on the lead variables are near zero.

Table A.5 - Testing the Parallel Trends Assumption for the Effect of Homeownership on Political Outcomes

\begin{tabular}{lcc|cc|cc}
\hline \hline & \multicolumn{2}{c}{ Commented $=1$} & \multicolumn{2}{c}{ Local Turnout $=1$} & \multicolumn{2}{c}{ Made Contribution $=1$} \\
& $(1)$ & $(2)$ & $(3)$ & $(4)$ & $(5)$ & $(6)$ \\
\hline Homeowner & 0.0557 & 0.0536 & 0.0223 & 0.0241 & 0.0053 & 0.0054 \\
& $(0.0083)$ & $(0.0084)$ & $(0.0002)$ & $(0.0002)$ & $(0.0001)$ & $(0.0002)$ \\
Homeowner $(\mathrm{t}+1)$ & -0.0001 & 0.0011 & -0.0071 & -0.0066 & 0.0002 & 0.0015 \\
& $(0.0092)$ & $(0.0094)$ & $(0.0002)$ & $(0.0002)$ & $(0.0002)$ & $(0.0002)$ \\
Homeowner $(\mathrm{t}+2)$ & & -0.0033 & & 0.0007 & & -0.0017 \\
& & $(0.0086)$ & & $(0.0002)$ & & $(0.0001)$ \\
Observations & 56,212 & 55,127 & $13,073,269$ & $11,588,248$ & $11,078,988$ & $10,331,474$ \\
Outcome Mean & 0.082 & 0.083 & 0.045 & 0.044 & 0.007 & 0.006 \\
Individual FEs & Yes & Yes & Yes & Yes & Yes & Yes \\
Year-by-Zip Code FEs & Yes & Yes & No & No & No & No \\
Year-by-State FEs & No & No & Yes & Yes & Yes & Yes \\
\hline \hline
\end{tabular}

Robust standard errors clustered by individual in parentheses. Columns 1 and 2 include only individuals who make a comment at some point over the study period, consistent with Table 2. Columns 5 and 6 include individuals registered to vote before the start of the study period, consistent with Table 4.

In columns 2, 4, and 6, I include two leads of the homeowner variable. For each outcome, the coefficient on the main effect remains similar, and the coefficients on both leads are near zero in all cases. Again, the only outcome that exhibits possible pre-trending is for political contributions in column 6 , where the coefficient on the one-period lead is positive and not negligible compared to the main effect. Overall, this table suggests that the parallel trends assumption might hold for local meeting participation and turnout, but we should perhaps be a little more cautious in our interpretation of the results for political donations. The political donations results are the most likely case where wealth could be a time-varying confounder that correlates both with the decision to purchase a home and with the propensity to make a political contribution, especially given that, among the types of political participation, making a contribution would be most likely to be a direct function of an individual's wealth. 
As such, the effects using home value-by-year fixed effects in Table 4 should be the most trusted of the specifications, which essentially makes comparisons among those with more plausibly similar levels of wealth - comparing homeowners with those who would eventually go on to purchase similarly priced homes.

\section{Figure A.4 - Dynamic Effect of Homeownership on Local Com- ments in Palo Alto, 2002-2010}

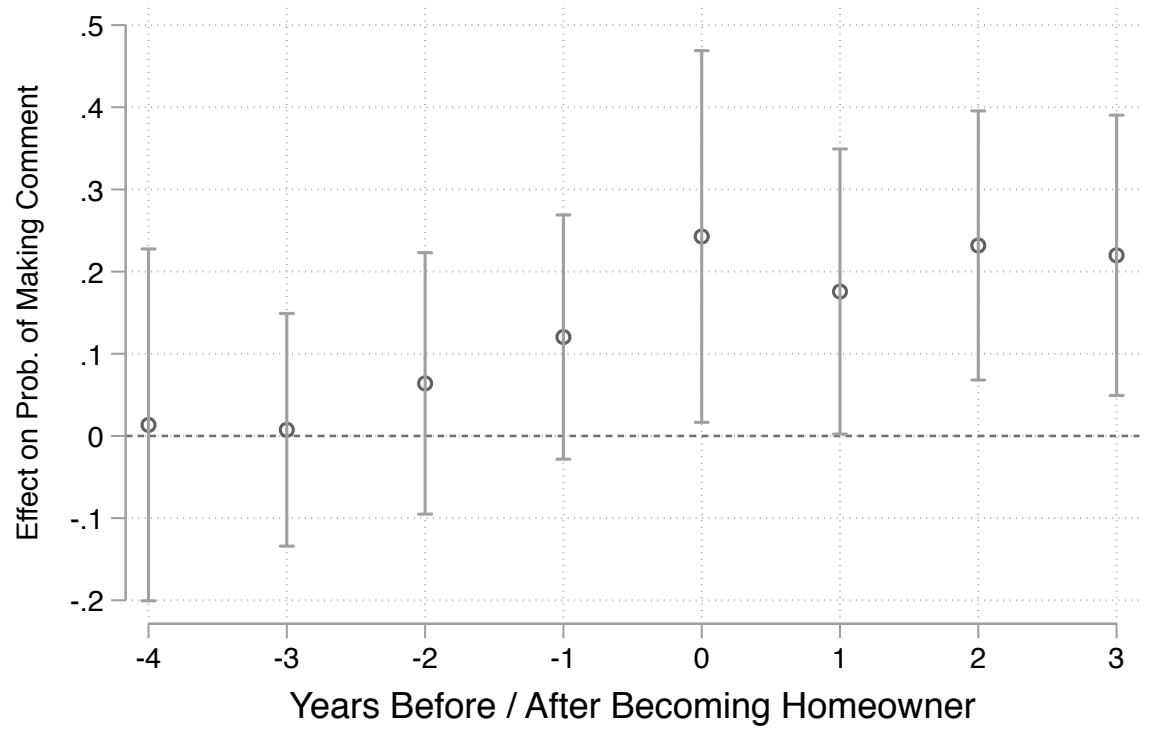

\footnotetext{
Note: In this analysis, I construct four leads of homeownership, a switching indicator, and three lags of homeownership. The four-period lead, for example, takes on a value of 1 if the individual is 4 years away from becoming a homeowner, and zero otherwise. As the plot shows, those who purchase homes become much more likely to comment in local city council meetings.
}

As another way to test the parallel trends assumption, I model the dynamic effect of homeownership on each outcome (Angrist and Pischke 2008; Autor 2003). In Figure A.4 I construct leads and lags of homeownership and plot its effect on the probabilility of making a contribution in each year in Palo Alto. The coefficients from - 4 to -1 represent effects in years prior to becoming a homeowner, while the coefficient at 0 indicates the first year in which the individual becomes a homeowner. The subsequent coefficients show how the effect of homeownership on commenting in Palo Alto evolves over time. Reassuringly, the effect of homeownership on making comments is indistinguishable from zero in the periods prior to homeownership, and they manifest only after an individual becomes a homeowner.

Next, in Figure A.5 I do the same exercise, modeling the dynamic effect of homeownership on commenting in local meetings, but this time for the city of Dallas. Again, the effect is substantively small and indistinguishable from zero in the periods prior to treatment, and they grow large in the post-treatment periods.

Finally, in Figure A.6 I model the dynamic effect of homeownership on commenting in local meetings for the city of Houston. The same pattern holds in Houston, where the effect of homeownership on commenting is substantively small and statistically insignificant in the pre-treatment periods, and then goes on to become substantively meaningful and statistically 
Figure A.5 - Dynamic Effect of Homeownership on Local Comments in Dallas, 2000-2018

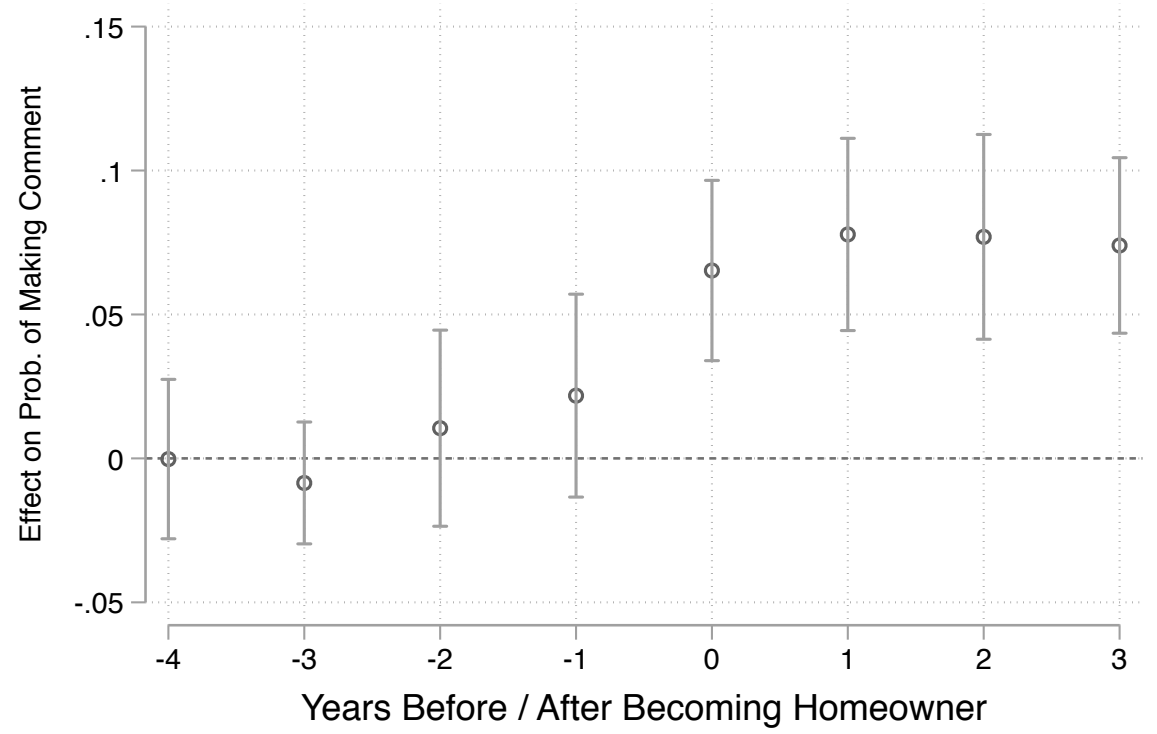

\begin{abstract}
Note: In this analysis, I construct four leads of homeownership, a switching indicator, and three lags of homeownership. The four-period lead, for example, takes on a value of 1 if the individual is 4 years away from becoming a homeowner, and zero otherwise. As the plot shows, those who purchase homes become much more likely to comment in local city council meetings.
\end{abstract}

significant in the post-treatment periods. Overall, the results in Figures A.4, A.5, and A.6 suggest the parallel trends assumption is likely to be valid for the results in Table 2 showing the effect of homeownership on the probability of making a public statement in a local city council meeting.

To validate the parallel trends assumption for the results in Table 3 on turnout in local elections, in Figure A.7 I do the same exercise of modeling the dynamic effect of homeownership, with local election turnout as the outcome. For local turnout, the effect of homeownership in the lead periods is near zero (but statistically significant because of the large sample size), and the effect jumps to over 2 percentage points after becoming a homeowner. Again, this is reassuring evidence that parallel trends might hold in this case.

Finally, to validate the parallel trends assumption for the results in Table 4 on political contributions, in Figure A.8 I do the same exercise of modeling the dynamic effect of homeownership, with an indicator for making a political contribution as the outcome. Here, the effect of homeownership in the lead periods is near zero, but positive and statistically significant in the year just before becoming a homeowner, and the effect grows large in the post-treatment periods. Similar to the findings in Table A.5, in Figure A.8 there is some evidence of possible pre-trending in the likelihood of making a political contribution. Again, this is consistent with the possibility of wealth being a time-varying confounder. Because political donations are monetary, it's likely to be more susceptible to confounding where individuals become wealthier, leading them to both purchase a home and to increase their 
Figure A.6 - Dynamic Effect of Homeownership on Local Comments in Houston, 2004-2014

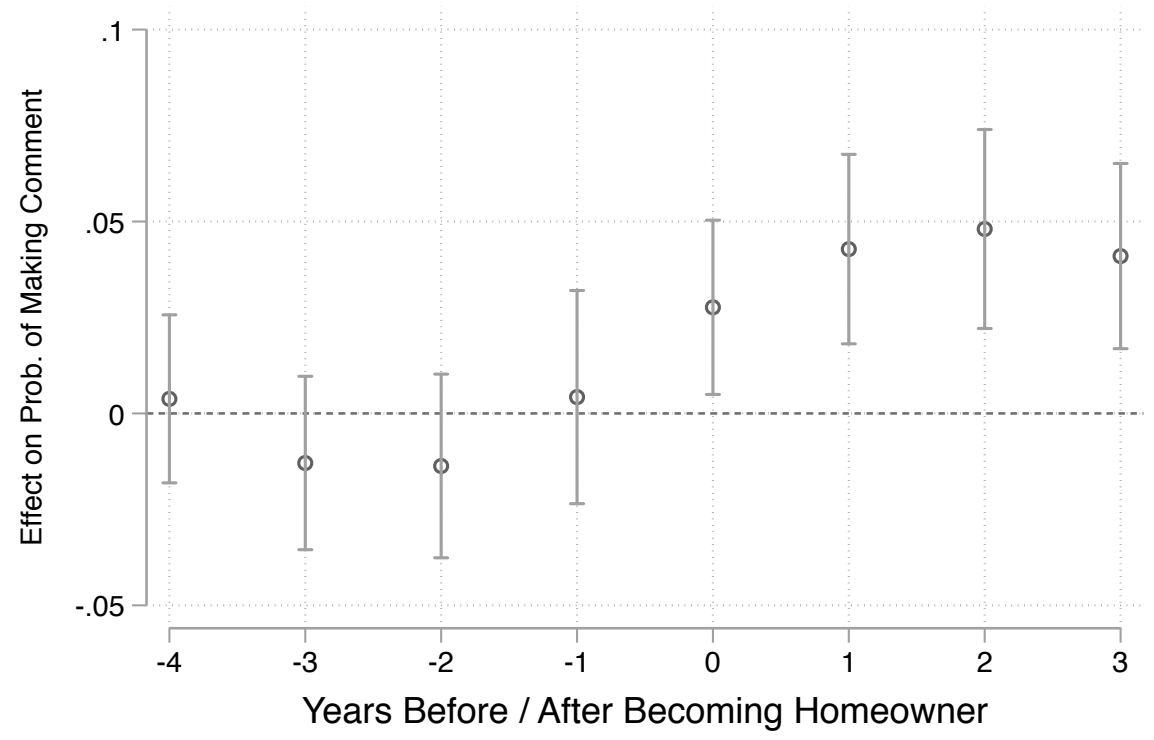

Note: In this analysis, I construct four leads of homeownership, a switching indicator, and three lags of homeownership. The four-period lead, for example, takes on a value of 1 if the individual is 4 years away from becoming a homeowner, and zero otherwise. As the plot shows, those who purchase homes become much more likely to comment in local city council meetings.

political donations. As such, we should be careful in interpreting the results where political donations are the main outcome.

Overall, these tests suggest the parallel trends assumption are likely to hold in the case of local comments and local turnout, but might be vulnerable to time-varying confounding in the case of political contributions. Nonetheless, for most results there is evidence that the parallel trends assumption likely holds. 
Figure A.7 - Dynamic Effect of Homeownership on Local Turnout

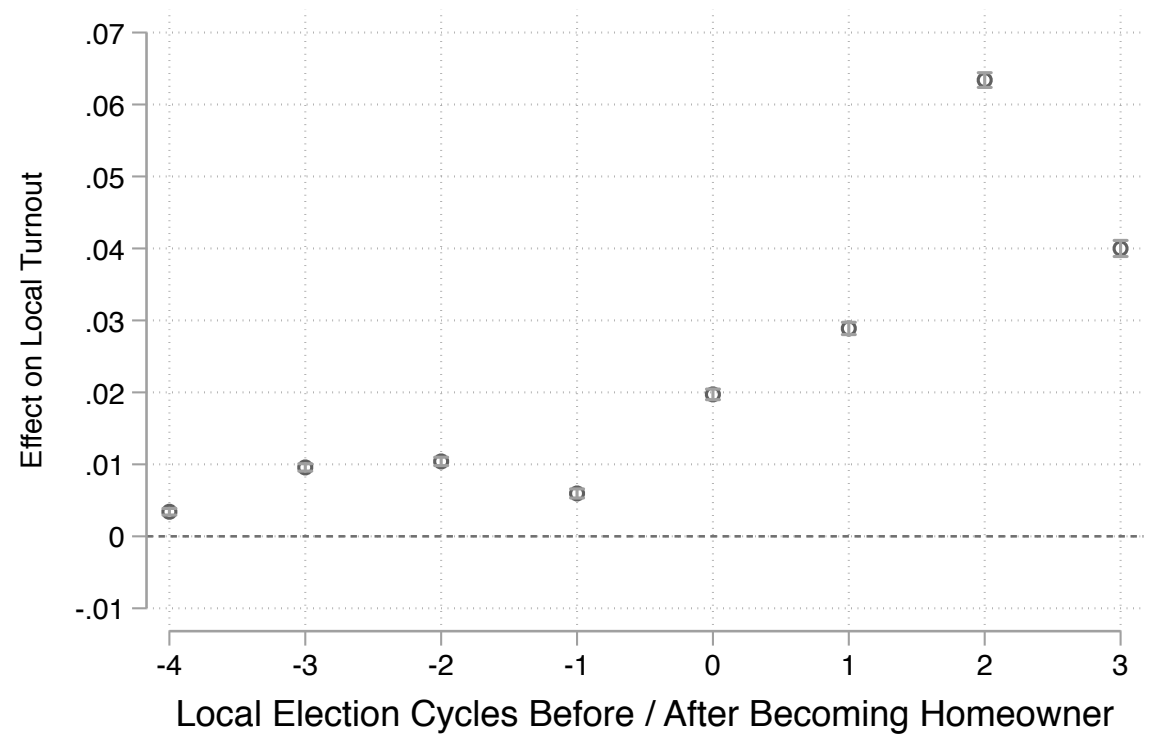

Note: In this analysis, I construct four leads of homeownership, a switching indicator, and three lags of homeownership. The four-period lead, for example, takes on a value of 1 if the individual is 4 local election cycles away from becoming a homeowner, and zero otherwise. As the plot shows, those who purchase homes become much more likely to participate in local elections. 
Figure A.8 - Dynamic Effect of Homeownership on Political Contributions

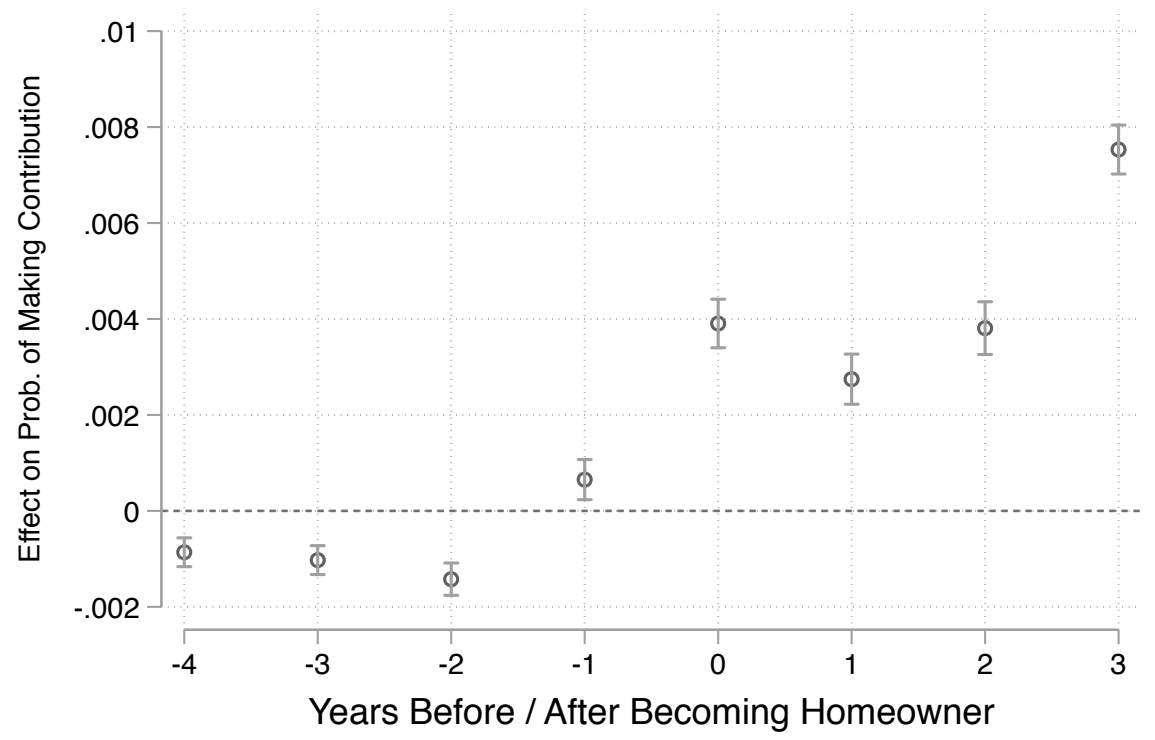

Note: In this analysis, I focus on individuals registered prior to 2000, and I construct four leads of homeownership, a switching indicator, and three lags of homeownership. The four-year lead, for example, takes on a value of 1 if the individual is 4 years from becoming a homeowner, and zero otherwise. As the plot shows, those who purchase homes become much more likely to make a political donation. 


\section{A.8 Estimating the Effect of Homeownership on Com- menting Across Home Value}

In this section, I estimate the heterogeneity in the size of the effect of homeownership on commenting in local meetings across home value. To do so, I estimate the following equation:

$$
\text { Commented }_{i t}=\beta_{0} \text { Homeowner }_{i t}+\beta_{1} \text { Homeowner }_{i t} * \log \left(\text { HomeValue }_{i}+\gamma_{i}+\delta_{t}+\epsilon_{i t}\right.
$$

where Commented $_{i t}$ is an indicator for whether individual $i$ comments at a local city council meeting in year $t$, and Homeowner $i$ is an indicator for whether individual $i$ is a property owner at any time in the year prior to the start of year $t$, and $\log \left(\right.$ HomeValue $_{i}$ is the home purchaser $i$ 's logged home value. The individual fixed effects are represented by $\gamma_{i}$, and zip code-by-year fixed effects are represented by $\delta_{t}$.

In Figure A.9 I estimate this equation. In the top left graph I use the pooled sample of the three cities, similar to column 2 of Table 2 , and then I plot $\left(\beta_{0}+\beta_{1} * \log (\right.$ HomeV alue $\left.)\right)$ across a range of home values. As the figure shows, the effect of homeownership on commenting is larger for purchasers of higher, rather than lower, valued homes. The top right figure shows the same thing but only using individuals in Palo Alto, similar to column 3 of Table 2. While it is noisy, the graph shows that the relationship between the size of the homeownership effect and the value of the purchaser's home is positive. In the bottom left figure I show the results for Dallas only, similar to column 4 of Table 2, and in the bottom right figure I show the results for Houston only, similar to column 5 of Table 2. In each case, the relationship between the size of the homeownership effect and the individual's purchased home value appears to be positive. 
Figure A.9 - Effect of Homeownership on Commenting, Across Home Value. This figure shows the effect of homeownership on commenting across the home purchaser's logged home value. The top left figure shows this relationship pooling across the three cities in the sample, the top right figure subsets to Palo Alto, the bottom left figure subsets to Dallas, and the bottom right figure subsets to Houston. In each case, the relationship between the effect of homeownership on commenting and the purchaser's logged home value is positive.
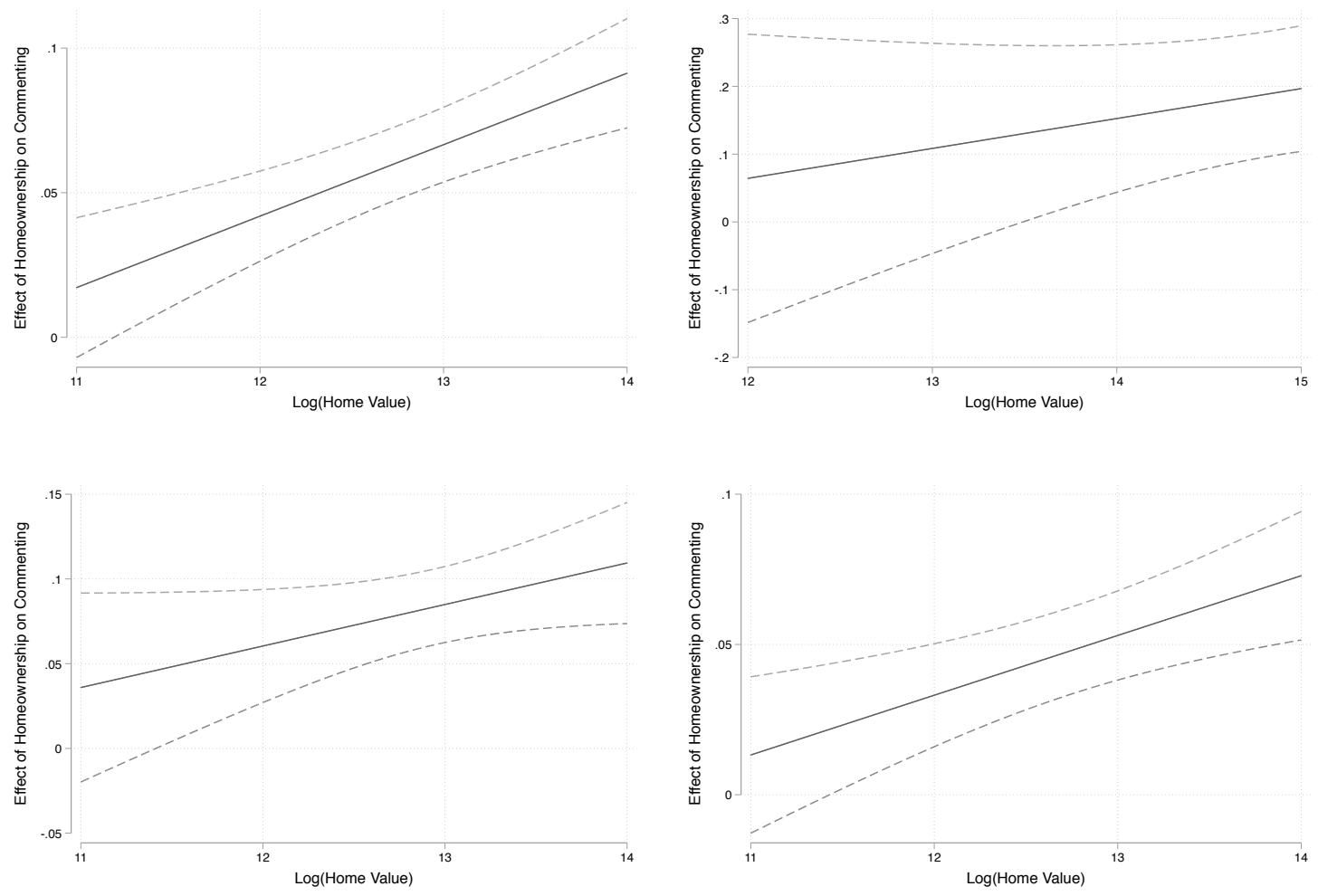


\section{A.9 Alternative Multi-Period Difference-in-Differences Estimator}

In this section, I consider an alternative multi-period difference-in-differences estimator: the weighted fixed effects (WFE) estimator proposed by Imai and Kim (2020). Building on recent work on the interpretation of multi-period difference-in-differences estimators (e.g., Goodman-Bacon 2018), this paper notes that the standard two-way fixed effects regression (including unit and time fixed effects), as I implement throughout most of the analyses in the main body of the paper, is equivalent to the difference-in-differences estimator with two units and two time periods, but this equvalence does not necessarily hold with many units receiving treatment across many time periods. Imai and Kim (2020) goes on to show that the multi-period difference-in-differences estimator is equivalent to the weighted twoway fixed effects estimator. I implement the nonparametric matching estimator using their wfe package in R. Because of the computational burden of estimating this nonparametric matching estimator, I limit the analysis to the results on commenting in local meetings (Table 2), where the number of observations are in the tens of thousands rather than the tens of millions, as in Tables 3 and 4 .

I show the results of the weighted fixed effects estimator in Table A.6. The columns mirror those of Table 2. As we can see, the coefficients remain similar in magnitude to, though less precisely esimated than, those in Table 2. Overall, this suggests that the twoway fixed estimator implemented in the main body of the paper, which I interpret as a multi-period difference-in-differences estimator, is unlikely to be misspecified, at least in the case of estimating the effect of homeownership on commenting in local city council meetings.

Table A.6 - Effect of Homeownership on Participation in City Council Meetings, 2000-2018, using Weighted Fixed Effects Estimation

\begin{tabular}{lccccc}
\hline \hline & & \multicolumn{5}{c}{ Commented $=1$} \\
& $(1)$ & $(2)$ & $(3)$ & $(4)$ & $(5)$ \\
\hline Homeowner & 0.033 & 0.031 & 0.140 & 0.039 & 0.021 \\
& $(0.012)$ & $(0.014)$ & $(0.104)$ & $(0.021)$ & $(0.016)$ \\
Observations & 83,580 & 53,541 & 6,831 & 16,290 & 30,420 \\
Number of Individuals & 5,978 & 3,873 & 759 & 1,086 & 2,028 \\
Sample & Pooled & Pooled & Palo Alto & Dallas & Houston \\
Always Registered & No & Yes & Yes & Yes & Yes \\
Individual FEs & Yes & Yes & Yes & Yes & Yes \\
Year-by-City FEs & Yes & Yes & Yes & Yes & Yes \\
\hline \hline
\end{tabular}

Robust standard errors clustered by individual in parentheses. The unit of observation is a person-year. Columns 2 through 5 restrict the sample to individuals registered to vote in the state before the panel. All columns restrict the sample to individuals who make a comment at some point over the length of the panel. 


\section{A.10 Estimating the Effect of Homeownership Across Urban and Rural Settings}

In this section, I estimate the effect of homeownership across urban and rural settings. To do so, I collect zip code-level information from the 2000 US Census. I code a zip code as urban if $100 \%$ of the zip code lies within an "Urbanized Area," defined by the US Census as an area that contains 50,000 or more people. I interact this indicator for whether an individual resides in an urban zip code with the homeownership treatment. The results for local election turnout are shown in Table A.7. I omit the specification with zip code-by-year fixed effects because the interaction term varies at the zip code level. The coefficient on homeownership can be interpreted as the effect of homeownership on local election turnout in rural zip codes, while the sum of the two coefficients can be interpreted as the effect of homeownership on local election turnout in urban zip codes. The table shows that the effect of homeownership is larger in urban zip codes. This is consistent with a story where individuals become especially motivated to participate in places where issues around housing are most salient, and in places where homeownership may be less likely to be a proxy for lifestyle changes like having a family or committing to a residence long-term. That said, as with any analysis that estimates the heterogeneous treatment effects, there are many other potential differences between the types of people who purchase homes in urban versus rural areas which may explain the heterogeneous effects, so we should be careful not to interpret these tests as proof of any particular mechanism. Nonetheless, these tests are informative insofar as they show that the effect of homeownership manifests in both urban and rural settings.

Table A.7 - Effect of Homeownership on Political Participation in Local California and Texas Elections, 2001-2017.

\begin{tabular}{lccc}
\hline \hline & \multicolumn{2}{c}{ Turnout in Local Election $=1$} \\
& $(1)$ & $(2)$ & $(3)$ \\
\hline Homeowner & 0.024 & 0.019 & 0.016 \\
& $(0.000)$ & $(0.000)$ & $(0.000)$ \\
Homeowner $\times$ Urban Zip Code & 0.017 & 0.017 & 0.025 \\
& $(0.001)$ & $(0.001)$ & $(0.001)$ \\
Observations & $13,337,892$ & $13,315,689$ & $6,965,568$ \\
Outcome Mean & 0.048 & 0.048 & 0.092 \\
Individual FEs & Yes & Yes & Yes \\
Year-by-State FEs & Yes & No & No \\
Year-by-Value-by-State FEs & No & Yes & No \\
Year-by-Age-by-State FEs & No & No & Yes \\
\hline \hline
\end{tabular}

Robust standard errors clustered by individual in parentheses. All columns include only individuals who become homeowners at some point during the study period. Year-by-Value fixed effects interact years with home value deciles. 


\section{A.11 Estimating the Effect of Homeownership Across Property Type}

In this section, I estimate the effect of homeownership across property type. As noted in the main body of the paper, the property records have a field for property type, and I include individuals as homeowners who purchase a single-family residence, duplex, condominium, or apartment. To estimate how the effect varies by property type, I interact the homeownership treatment with an indicator for whether an individual purchases a property designated as a single family residence. The results for commenting in local meetings are shown in Table A.8, and the columns mirror those in Table 2. The coefficient on homeownership can be interpreted as the effect of homeownership on commenting in for individuals who purchase a property that is not designated as a single family residence (SFR), while the sum of the two coefficients can be interpreted as the effect of homeownership on commenting for individuals who purchase an SFR. The table shows that the effect of homeownership appears for both SFR and non-SFR purchasers. It could be that the effect is larger for those who purchase an SFR - each of the coefficients on the interaction terms are positive - but the estimates are quite noisy. In Palo Alto, for example, very few individuals purchase a property that is not designated as an SFR, so the estimates of how the effect varies on this dimension are very noisy and not particularly informative.

Table A.8 - Effect of Homeownership on Participation in City Council Meetings, 2000-2018.

\begin{tabular}{lccccc}
\hline \hline & \multicolumn{5}{c}{ Commented $=1$} \\
& $(1)$ & $(2)$ & $(3)$ & $(4)$ & $(5)$ \\
\hline Homeowner & 0.007 & 0.037 & 0.013 & 0.041 & 0.036 \\
& $(0.017)$ & $(0.019)$ & $(0.222)$ & $(0.027)$ & $(0.022)$ \\
Homeowner $\times$ Single Family Residence & 0.049 & 0.021 & 0.181 & 0.036 & 0.008 \\
& $(0.017)$ & $(0.020)$ & $(0.226)$ & $(0.031)$ & $(0.023)$ \\
Observations & 83,580 & 53,496 & 6,831 & 16,275 & 30,390 \\
Number of Individuals & 5,978 & 3,870 & 759 & 1,085 & 2,026 \\
Outcome Mean & 0.077 & 0.083 & 0.161 & 0.055 & 0.081 \\
Sample & Pooled & Pooled & Palo Alto & Dallas & Houston \\
Always Registered & No & Yes & Yes & Yes & Yes \\
Individual FEs & Yes & Yes & Yes & Yes & Yes \\
Year-by-Zip Code FEs & Yes & Yes & Yes & Yes & Yes \\
\hline \hline
\end{tabular}

Robust standard errors clustered by individual in parentheses. The unit of observation is a person-year. Columns 2 through 5 restrict the sample to individuals registered to vote in the state before the panel. All columns restrict the sample to individuals who make a comment at some point over the length of the panel.

To generate estimates with a bit more statistical precision, in Table A.9 I estimate the heterogeneity in the homeownership effect across property type, but use turnout in local 
elections as the outcome. Again, we can interpret the effect on homeownership term as the effect among purchasers of non-SFR properties, and the sum of the two coefficients represents the effect among purchasers of SFR properties. The coefficients on the interaction term are small, and are sometimes positive and sometimes negative, suggesting that the effect does not vary drastically by whether or not the individual purchased a single-family residence or not. These results are consistent with a story where homeownership leads to an increase in local turnout both for individuals who might be purchasing properties at the same time as other lifestyle changes (SFR purchasers planning for a family, for example), and for those who might not be (non-SFR purchasers). Again, caveats abound - with this data it is hard to attribute effect heterogeneity, or lack thereof, as evidence for specific mechanisms. Survey work might be able to speak more directly to these types of mechanisms (e.g., Hankinson 2018; Marble and Nall 2018) and offers a promising avenue for future work.

Table A.9 - Effect of Homeownership on Political Participation in Local California and Texas Elections, 2001-2017.

\begin{tabular}{lcccc}
\hline \hline & \multicolumn{3}{c}{ Turnout in Local Election $=1$} \\
& $(1)$ & $(2)$ & $(3)$ & $(4)$ \\
\hline Homeowner & 0.025 & 0.021 & 0.025 & 0.025 \\
& $(0.001)$ & $(0.001)$ & $(0.001)$ & $(0.001)$ \\
Homeowner $\times$ Single Family Residence & 0.003 & 0.007 & -0.002 & -0.004 \\
& $(0.001)$ & $(0.001)$ & $(0.001)$ & $(0.001)$ \\
Observations & $13,365,189$ & $13,365,189$ & $13,342,986$ & $6,980,535$ \\
Outcome Mean & 0.048 & 0.048 & 0.048 & 0.092 \\
Individual FEs & Yes & Yes & Yes & Yes \\
Year-by-State FEs & Yes & No & No & No \\
Year-by-Zip Code FEs & No & Yes & No & No \\
Year-by-Value-by-State FEs & No & No & Yes & No \\
Year-by-Age-by-State FEs & No & No & No & Yes \\
\hline \hline
\end{tabular}

Robust standard errors clustered by individual in parentheses. All columns include only individuals who become homeowners at some point during the study period. Year-byValue fixed effects interact years with home value deciles. 


\section{A.12 Estimating the Effect of Homeownership on Lo- cal Turnout for Recent Years}

One limitation of the analyses on local turnout is that I use a recent version of the voter file. Of course, the composition of voter files changes over time, as voters change residences. In many cases, an individual's voter ID number, and therefore turnout history, is preserved if they move within the same state, assuming that they report their previous registration information correctly. If this information is not preserved, however, I might mistakenly code an individual in the voter file as not having voted when they had indeed voted at a previous residence. To the extent that this happens to individuals who become homeowners, this would upward bias the estimates in Table 3. To avoid this potential bias, I take two approaches. The first is simply to show how the results vary when I increasingly subset to recent years, where this information is more likely to have been preserved over the course of the study period. Table A.10 estimates the effect of homeownership on turnout in local elections, but instead of using the full study period of 2001-2017, I subset to recent years. In column 1, for example, I include only the time period from 2003-2017. In column 2, I include only the time period from 2005-2017, and so on. The estimates remain reasonably stable as I increasingly subset to recent years, which suggests that the issue noted above does not seem to be exerting a large bias on the the main results. The second, approach, which I show in Section A.14, limits the local turnout analysis to individuals who were recorded in the voter file as having been registered in the state prior to 2001. This changes the composition of the sample, the effect in that case is estimated among long-time registrants, but it helps to avoid the problem noted above. Again, the results in that analysis are similar to those in Table 3.

Table A.10 - Effect of Homeownership on Political Participation in Local California and Texas Elections

\begin{tabular}{lcccccc}
\hline \hline & \multicolumn{7}{c}{ Turnout in Local Election $=1$} & \\
& $(1)$ & $(2)$ & $(3)$ & $(4)$ & $(5)$ & $(6)$ \\
\hline Homeowner & 0.021 & 0.014 & 0.025 & 0.023 & 0.022 & 0.017 \\
& $(0.000)$ & $(0.000)$ & $(0.000)$ & $(0.000)$ & $(0.001)$ & $(0.001)$ \\
Observations & $11,880,168$ & $10,395,147$ & $8,910,126$ & $7,425,105$ & $5,940,084$ & $4,455,063$ \\
Outcome Mean & 0.051 & 0.056 & 0.041 & 0.043 & 0.043 & 0.047 \\
Year Sample & $2003+$ & $2005+$ & $2007+$ & $2009+$ & $2011+$ & $2013+$ \\
Individual FEs & Yes & Yes & Yes & Yes & Yes & Yes \\
Year-by-Zip Code FEs & Yes & Yes & Yes & Yes & Yes & Yes \\
\hline
\end{tabular}

Robust standard errors clustered by individual in parentheses. All columns include only individuals who become homeowners at some point during the study period. 


\section{A.13 Additional Results for Comments in City Council Meetings}

In this section, I include additional results for the effect of homeownership on commenting behavior in local city council meetings. In Table A.11 I reproduce Table 2 but use total number of comments that an individual makes in a given year as the outcome, rather than an indicator for whether or not an individual makes at least one comment in a given year. The results are substantively quite similar. Homeownership leads to increases in the total number of comments made in a year by an individual, but the size of the effect varies dramatically across context. Individuals become much more likely to participate in Palo Alto city council meetings once they become homeowners (column 3), the effect is statistically indistinguishable from zero in Dallas (column 4), and the effect is positive but slightly more modest in Houston (column 5). Overall, this is consistent with the interpretation that homeownership motivates individuals to participate in local politics, but the extent to which it motivates them depends on the context.

Table A.11 - Effect of Homeownership on Participation in City Council Meetings, 2000-2018.

\begin{tabular}{lccccc}
\hline \hline & & \multicolumn{4}{c}{$\log ($ Comments +1$)$} \\
& $(1)$ & $(2)$ & $(3)$ & $(4)$ & $(5)$ \\
\hline Homeowner & 0.039 & 0.043 & 0.129 & 0.054 & 0.035 \\
& $(0.004)$ & $(0.006)$ & $(0.042)$ & $(0.014)$ & $(0.007)$ \\
Observations & 83,580 & 53,496 & 6,831 & 16,275 & 30,390 \\
Number of Individuals & 5,978 & 3,870 & 759 & 1,085 & 2,026 \\
Outcome Mean & 0.077 & 0.083 & 0.161 & 0.055 & 0.081 \\
Sample & Pooled & Pooled & Palo Alto & Dallas & Houston \\
Always Registered & No & Yes & Yes & Yes & Yes \\
Individual FEs & Yes & Yes & Yes & Yes & Yes \\
Year-by-Zip Code FEs & Yes & Yes & Yes & Yes & Yes \\
\hline \hline
\end{tabular}

Robust standard errors clustered by individual in parentheses. The unit of observation is a person-year. Columns 2 through 5 restrict the sample to individuals registered to vote in the state before the panel. All columns restrict the sample to individuals who make a comment at some point over the length of the panel. 


\section{A.14 Additional Results for Local Turnout}

In this section, I include additional results for the effect of homeownership on local election turnout.

Table A.12 - Effect of Homeownership on Political Participation in Local California and Texas Elections, Full Sample, 2001-2017.

\begin{tabular}{lcccc}
\hline \hline & \multicolumn{4}{c}{ Turnout in Local Election $=1$} \\
& $(1)$ & $(2)$ & $(3)$ & $(4)$ \\
\hline Homeowner & 0.014 & 0.014 & 0.016 & 0.021 \\
& $(0.000)$ & $(0.000)$ & $(0.000)$ & $(0.000)$ \\
Observations & $28,428,993$ & $28,428,993$ & $16,229,826$ & $20,402,820$ \\
Outcome Mean & 0.044 & 0.044 & 0.049 & 0.062 \\
Individual FEs & Yes & Yes & Yes & Yes \\
Year-by-State FEs & Yes & Yes & No & No \\
Year-by-Zip Code FEs & No & Yes & No & No \\
Year-by-Value-by-State FEs & No & No & Yes & No \\
Year-by-Age-by-State FEs & No & No & No & Yes \\
\hline \hline
\end{tabular}

Robust standard errors clustered by individual in parentheses. Column 3 includes only individuals who become homeowners at some point during the study period. Year-by-Value fixed effects interact years with home value deciles.

In Table A.12 I reproduce Table 3 but use the full sample of individuals in the voter file and the property records, regardless of whether or not they purchase a home at some point during the study period. In the main body of the paper, I included only individuals who had purchased a home at some point during the study period to make more plausible counterfactual comparisons - essentially comparing trends in turnout for individuals who become homeowners to those who were not homeowners but would go on to be later in the panel. The results in Table A.12 are nearly identical to those in Table 3.

In Table A.13 I reproduce Table 3 but subset to individuals who were listed in the voter file as having been registered to vote in the state prior to the start of the study period, meaning prior to 2001. The composition of the sample changes slightly here - I am estimating the effect only among long-time registrants - and the effects attenuate slightly, but remain positive and both substantively and statistically significant. 
Table A.13 - Effect of Homeownership on Political Participation in Local California and Texas Elections, Long-Time Registrants, 2001-2017.

\begin{tabular}{lcccc}
\hline \hline & \multicolumn{4}{c}{ Turnout in Local Election $=1$} \\
& $(1)$ & $(2)$ & $(3)$ & $(4)$ \\
\hline Homeowner & 0.013 & 0.013 & 0.013 & 0.007 \\
& $(0.001)$ & $(0.001)$ & $(0.001)$ & $(0.001)$ \\
Observations & $7,744,581$ & $7,744,581$ & $4,500,756$ & $7,737,003$ \\
Outcome Mean & 0.123 & 0.123 & 0.140 & 0.123 \\
Individual FEs & Yes & Yes & Yes & Yes \\
Year-by-State FEs & Yes & Yes & No & No \\
Year-by-Zip Code FEs & No & Yes & No & No \\
Year-by-Value-by-State FEs & No & No & Yes & No \\
Year-by-Age-by-State FEs & No & No & No & Yes \\
\hline \hline
\end{tabular}

Robust standard errors clustered by individual in parentheses. All columns subset to individuals registered to vote prior to the study period. Column 3 includes only individuals who become homeowners at some point during the study period. Year-by-Value fixed effects interact years with home value deciles. 


\section{A.15 Additional Results for Contributions}

In this section, I include additional results for the effect of homeownership on political contributions.

Table A.14 - Effect of Homeownership on Political Contributions, Full Sample, 2000-2014.

\begin{tabular}{lcccc}
\hline \hline & \multicolumn{4}{c}{ Made Itemized Contribution $=1$} \\
& $(1)$ & $(2)$ & $(3)$ & $(4)$ \\
\hline Homeowner & 0.003 & 0.003 & 0.002 & 0.005 \\
& $(0.000)$ & $(0.000)$ & $(0.000)$ & $(0.000)$ \\
Observations & $49,874,285$ & $49,874,285$ & $28,443,052$ & $35,843,582$ \\
Outcome Mean & 0.003 & 0.003 & 0.004 & 0.003 \\
Individual FEs & Yes & Yes & Yes & Yes \\
Year-by-State FEs & Yes & No & No & No \\
Year-by-Zip Code FEs & No & Yes & No & No \\
Year-by-Value FEs & No & No & Yes & No \\
Year-by-Age FEs & No & No & No & Yes \\
\hline \hline
\end{tabular}

Robust standard errors clustered by individual in parentheses. All columns include all individuals in the voter file and property records, regardless of voter registration status. Column 3 restricts the sample to those who become homeowners at some point during the study period.

First, in Table A.14 I reproduce Table 4 but use the full sample of individuals in the voter file and the property records, regardless of their voter registration status or date. The reasoning is the same as described in Section A.14. Similar to the local turnout, the results for contributions using the full sample Table are nearly identical to those in Table 4, which uses only individuals registered to vote prior to 2000. In Table A.15 I estimate the effect on political contribution amount rather than an indicator for whether an individual made a contribution in a given year. The results suggest that homeownership leads to an increase not just in likelihood of donating, but also in the contribution amount. 
Table A.15 - Effect of Homeownership on Political Contribution Amount, 2000-2014.

\begin{tabular}{lcccc}
\hline \hline & \multicolumn{4}{c}{$\log ($ Contributions +1$)$} \\
& $(1)$ & $(2)$ & $(3)$ & $(4)$ \\
\hline Homeowner & 0.028 & 0.027 & 0.012 & 0.029 \\
& $(0.001)$ & $(0.001)$ & $(0.001)$ & $(0.001)$ \\
Observations & $11,826,502$ & $11,826,502$ & $7,028,296$ & $11,814,246$ \\
Outcome Mean & 0.036 & 0.036 & 0.048 & 0.037 \\
Individual FEs & Yes & Yes & Yes & Yes \\
Year-by-State FEs & Yes & No & No & No \\
Year-by-Zip Code FEs & No & Yes & No & No \\
Year-by-Value FEs & No & No & Yes & No \\
Year-by-Age FEs & No & No & No & Yes \\
\hline \hline
\end{tabular}

Robust standard errors clustered by individual in parentheses. All columns include only individuals who were registered to vote in the state prior to the start of the study period. Column 3 restricts the sample to those who become homeowners at some point during the study period. 


\section{A.16 Topic Model}

For illustration, I include the single subject or public comment that loads most heavily on each topic. The most common words in each topic are in italics, followed by the full text of the item or comment, city, and year.

- Topic 1: home, properti, year hous, build, need, live: "appeared and stated that the city established the ordinance to protect the character of a neighborhood when deed restrictions were unclear or silent and theirs were filed in 1925 and he had a plat which clearly showed lot sizes of 6,000 square feet; that paragraph 5 of their deed restrictions clearly prohibited multi family housing and they had house hunters refusing their block because it already looked like multi housing, the house next to him had been on the market over a year; that paragraph 5 stated no apartment house or duplex designed to be occupied by more than two families would be permitted in the addition and the object of the provision was to prohibit multiple housing throughout the entire addition and so more than one duplex on a lot would be a violation; that currently there was nothing to prohibit a developer from subdividing an original lot and then putting a duplex on each new subdivided lot and lots smaller than 6,000 square feet would render the prohibition of multiple housing meaningless and the ordinance would clarify many deed restrictions with respect to prohibition of multiple housing; that over the last 20 years subdivided lots had gone down and Dr. Gould purchased two subdivided lots and combined them again into the original 6,000 square foot lot and purchased the adjacent lot to preserve it when a builder was about to subdivide it and seven of the ten duplexes were converted to single family over the last 20 years." Houston, 2009.

- Topic 2: communiti, program, depart, polic, issu, board, center: "spoke on The Committee to Honor J.B. Jackson Jr. and Elsie Faye Heggins" Dallas, 2003.

- Topic 3: get, said, want, came, back problem, offic: "appeared and stated that she was present as she believed proper police procedure was not followed yesterday when she was pulled over by police off 288 and Reed Road; that while being pulled over last night she thought she followed proper procedure and pulled over and rolled down her window, as the officer approached he asked her for her license and to step out of the vehicle and he pulled open the door and she got out; that they were walking to the back of the vehicle and he asked if she would like to know why she was pulled over and said because her license plate light was out and she said she saw that and had not known and would get it fixed; that the other officer got out of the patrol car and came over and they asked she put her hands on the vehicle and asked if she had drugs or weapons and she said no; that they then asked if she had anything in her pockets and she said yes and they asked she take it out and when she reached into her pocket they said you should never reach in a pocket in front of an officer, it was a bad move; and she said she was following instructions; that one officer pushed her toward the patrol car and said to walk with him and the other officer went to her vehicle and had not said what he was to do, but he started going through everything in her car and when she asked why, the officer with her said she may be going to jail and they needed to take inventory of everything in the car." Houston, 2008. 
- Topic 4: council, project, palo, alto, support, plan, citi: "said he did not oppose the Opportunity Center but he did have some suggestions because of some problem wording in particular Attachment E condition 10 page 6 of the staff report (CMR:157:03). The sentence read 'Prior to occupancy the results of an outdoor noise audit of the completed project shall be submitted to the Planning Division for its review and approval. The Planning Division may require additional sound attenuation measures if it determines the noise levels are inconsistent with the Comp Plan standards.' The statement was inconsistent with the rest of the staff report. His alternative statement was 'Prior to occupancy the results of an independent study of the completed project shall be submitted to the Planning Division to determine compliance with the Comp Plan and noise ordinance. The Planning Division shall require additional sound attenuation measures if the independent study determines the noise levels are inconsistent with the Comp Plan or Palo Alto noise ordinance standards."' Palo Alto, 2003.

- Topic 5: district, public, histor, improv, ordin, vote, height: "appeared and stated that she lived in Heights West and strongly supported the historic preservation amendment, though unhappy with the transition procedures and encouraged Council to not further amend the ordinance and urged a yes vote." Houston, 2010.

- Topic 6: present, time, call, speak, name, reserv, case: "had reserved time to speak but was not present when her name was called." Houston, 2004.

- Topic 7: houston, present, citi, council, ask, want, work: "appeared and stated that he was an independent contractor and a small business owner, they filed and paid their taxes as such, they would be a franchise owner under the Super Shuttle Agreement, which would take their business to the next level, as an independent contractor they leased their operating equipment, as a franchise they would own their operating equipment, that the difference between a McDonalds franchise owner and a Super Shuttle franchise owner was nothing at all, they were both small business owners, that Super Shuttle was a group of franchise owners organized under World Class Systems, the reason they needed exclusivity was so that when residential shuttle service develops in Houston they would not end up with the same rogue marketing all shuttles provide, it looked bad, their togetherness was demonstrated by their attendance today, and asked everyone present with him today to stand, they were Express Shuttle, that City Council's indecision had inadvertently affected 40 minority businessmen as a favor to one minority business, that City Council had put 100 family members lives on hold with not making a decision regarding the issue, that many of them had driven professionally for many years and wished to continue to do so under a system that would allow them to continue to be successful and take care of their minority families." Houston, 2006.

- Topic 8: park, neighborhood, street, traffic, area, develop, communiti: "appeared and stated that a proposed development would affect two adjoining neighborhoods Lynn Park and Hiram Village and discussed concerns with future traffic safety and congestion in their area of Weslayan and Richmond; and urged the exit not be into their residential area, but instead on Weslayan and West Alabama." Houston, 2012. 
- Topic 9: state, item, support, agenda, inform, flood, spoke: "appeared and spoke in support of the smoking ban, Agenda Item 39g, and stated that studies showed concerns of a decline in revenue for bars with no smoking was overblown; that in California where it was banned the bars were full; that the entire concept of leaving safety hazards in the hands of a business for voluntary elimination was silly and made no sense; and urged the ordinance be passed." Houston, 2006.

- Topic 10: citi, dalla, cost, hear, fund, financ, code: "spoke on Item 72: A public hearing to receive comments to amend the City of Dallas Thoroughfare Plan to change the dimensional classifications of: (1) McKinney Avenue between Allen Street and Harvard Avenue from an existing couplet (EXST CPLT) to a special three-lane undivided (SPCL 3U) roadway within 60-feet to 80-feet of right-of-way; (2) Allen Street between McKinney Avenue and Carlisle Street from an existing couplet (EXST CPLT) to a special three-lane undivided (SPCL 3U) roadway within 60-feet of right-of-way; (3) Carlisle Street between Allen Street and Cole Avenue from an existing couplet (EXST CPLT) to a special three-lane undivided (SPCL 3U) roadway within 60-feet of rightof-way; and (4) Cole Avenue between Carlisle Street and Harvard Avenue from an existing couplet (EXST CPLT) to a special three-lane undivided (SPCL 3U) roadway within 60-feet to 80-feet of right-of-way; and at the close of the hearing, authorize an ordinance implementing the change." Dallas, 2016. 